\title{
The Institutional Causes of China's Great Famine, 1959-1961*
}

\author{
Xin Meng ${ }^{\dagger} \quad$ Nancy Qian ${ }^{\ddagger} \quad$ Pierre Yared $^{\S}$
}

November 18, 2009

\begin{abstract}
We investigate the institutional theory of famine in the context of the largest famine in history: China's Great Famine 1959-61. First, we provide evidence inconsistent with the traditional theory of famine which states that famines are caused by national food production falling below per-capita subsistence needs. We show that even though food production declined in 1959, national food production remained well above per-capita subsistence needs, implying that the famine was caused by institutional failure. Second, we provide evidence which cannot be reconciled with the conventional institutional mechanism for the propagation of famines as described by Sen (1981). Using historic data, we show that rural regions that produced more food in 1959 actually suffered higher mortality during the famine. Finally, we reconcile these two facts with a model of constrained optimal policy which explains a new institutional mechanism for the propagation of famine. Our model implies that government policy, which is constrained by imperfect information and limited bureaucratic capacity, can amplify the rise in mortality resulting from a downturn in aggregate food production and can cause this rise in mortality to be increasing in local food production. A counterfactual exercise suggests that the presence of free markets for food would generate lower mortality relative to the constrained optimal policy. This is because free markets incorporate the aggregate decline in food production into the price of food, resulting in a more equal cross-regional decline in food consumption.
\end{abstract}

Keywords: Famines, Institutions, Development, Socialist Planning, History

JEL Classification: O43, N3, O1, P21

*We thank Daron Acemoglu, Robin Burgess, Sylvain Chassang, Claudia Goldin, Mikhail Golosov, Michael Kremer, Roger Myerson, Nathan Nunn, Torsten Persson, Canice Prendergast, Andrei Shleifer, Chad Syverson and the partcipants at the Harvard History Tea for their insights; and Ang Sun and Katherine Wilson for excellent research assistance.

$\dagger$ Australian National University, RSSS. email: xin.meng@anu.edu.au

${ }^{\ddagger}$ Yale University, NBER, CEPR, BREAD. email: nancy.qian@yale.edu.

${ }^{\S}$ Columbia University. email: pyared@columbia.edu. 


\section{Introduction}

In the twentieth century, over 100 million people have perished from famines, more than in both World Wars combined. ${ }^{1}$ China's Great Famine which began in the winter of 1959/60 and lasted until 1961, is the most severe famine in history, claiming the lives of between 17 and 30 million people. ${ }^{2}$ Famines do not only kill, but they are perilous to the survivors who suffer from health complications for decades afterwards. ${ }^{3}$

There are two major theories regarding the cause of famine. The traditional theory of famine is that they are caused by a reduction in aggregate food production to below per capita subsistence levels for the entire population. According to this theory, famine cannot be avoided absent an increase in aggregate food supply. In contrast, the institutional theory of famine proposed in the seminal work of Sen (1981), which was largely based on his detailed study of the Bengal case, aruges that famines can occur even in the absence of such an aggregate food shortage if institutions for food redistribution are not in place. The mechanism underlying this theory predicts a precise geographic pattern in the propagation of famine: there is a rise in the inequality of food production, and low food production regions are incapable of acquiring food from high food production regions, leading to famine in low production regions. Accordingly, such an outcome could be avoided in the presence of political and economic institutions which facilitate the transfer of food from high to low food production regions. ${ }^{4}$

With the exception of the work of Sen (1981), research on famines has not been able to reject the traditional theory of famine. This is because the primary cause of most famines such as the Irish Potato Famine (1845-52) and the Ethiopian Famine (1984-85) is arguably a fall in aggregate food production to below subsistence needs. Hence, while institutional channels may have worsened these famines, existing studies have not shown that they could have altogether been prevented in the presence of good institutions. As such, existing studies do not provide any formal analysis of the institutional theory of famine. ${ }^{5}$

In this paper we investigate the institutional theory and the underlying mechanisms of institution-driven famines in the context of China's Great Famine (1959-61). Our paper makes three contributions. First, we use newly available historic data to provide evidence

\footnotetext{
${ }^{1}$ See Sen (1981) and Ravallion (1997).

${ }^{2}$ See Coale (1981), Yao (1999), Peng (1987), Ashton et al. (1984) and Banister (1987).

${ }^{3}$ In a companion paper on the long run consequences of China's Great Famine on survivors, Meng and Qian (2009) provides a thorough literature review on the effects of famine.

${ }^{4}$ Sen argues that in the case of Bengal, bad rains reduced local production in certain regions and that these regions were unable to purchase food from high production regions and thus experienced famine. Sen links the causes of market failure to the inability of farmers to borrow to purchase food and to the British government's hoarding of food for military purposes which distorted the price of food to an excessively high level.

${ }^{5}$ Dreze (1999) provides an overview of recent economic studies on famines. For studies of the Irish Famine, see studies such as Hickson and Turner (2008), McGreggor (1989), O'Boyle (2006), O'Grada et al. (2006), and O'Rourke, (1902). For an overview of the Ethiopia Famine, see Webb (1994). A recent study by Ellman (2002) examines historic data from the Soviet era and finds that while institutions invariably exacerbated the famine of 1932-33, there was an aggregate food shortage due to bad harvests. Also, see Vallain (2002).
} 
inconsistent with the traditional theory and consistent with the institutional theory of famine. Specifically, we show that the drop in aggregate production in 1959 was not sufficiently large enough to create a food shortage below per capita subsistence needs. (Note that because almost all calories came from grains for most Chinese populations at the time, we use the terms grain and food interchangeably in this paper). While this fact has been informally discussed in other studies and anecdotal accounts, we are the first to support this fact with evidence from historic data on population and production. Second, we provide evidence which cannot be reconciled with Sen's (1981) conventional mechanism for how institutions propagate famines. Specifically, we use historic data to show that rural regions that produced more food in 1959 actually suffered higher mortality during the famine. To the best of our knowledge, this fact has not received any attention in other academic studies. ${ }^{6}$ Our final contribution is to reconcile these two facts with a model of constrained optimal policy which explains a new institutional mechanism for the propagation of famine. Our model implies that government policy, which is constrained by imperfect information and limited bureaucratic capacity, can amplify the rise in mortality resulting from a downturn in aggregate food production in way such that the severity of the famine is increasing in food production.

More specifically, first, we show that there is no evidence that the famine was caused by an aggregate food shortage below per capita subsistence needs. In 1959, aggregate agricultural food production fell by approximately $13 \%$ percent over the previous year's production, approximately $18 \%$ percent below the estimated trend as food production had been steadily rising from at a rate of $4 \%$ percent from 1952 to 1958 . However, given that China's population had not increased dramatically since 1956 when production was equivalent to that of 1959, this drop was not sufficiently large enough for the level of aggregate food production to fall below the per-capita subsistence needs of the population. This is clearly illustrated in Figure 1. Although food production in 1959 was approximately 3\% less than the level needed to prevent starvation, it was more than twice as much as what was needed to prevent famine mortality. ${ }^{7}$ Therefore, the famine which killed between 17 and 30 million people, most of whom died in the first winter of 1959/60, must have been caused by an institutional mechanism which amplified the effect of the reduction in aggregate food production.

Second, we show that the geographic pattern of famine in China is inconsistent with the conventional institutional mechanism for the propagation of famine. According to this mechanism, famines should occur in low food production regions which are unable to acquire food from high production regions because of missing economic and political institutions. Contrary to this prediction, we find a positive correlation between food production and famine mortality across Chinese rural regions. This is illustrated in Figure 2 , which plots the residuals from a province-level bivariate regression of the mortality rate in 1959 and 1960 on the amount of grain production. It shows a negative correlation.

\footnotetext{
${ }^{6}$ The positive correlation between famine severity and grain production has been mentioned in the companion paper Meng and Qian (2009). Amongst non-academic sources, it was described informally in Becker's (1996) book on China's famine.

${ }^{7}$ We define 2,240 calories per day as the level needed to prevent starvation, and 900 calories per day as teh level needed to prevent mortality. See section 4 for a detailed discussion.
} 
Consistent with anecdotal accounts, we also find virtually no evidence of famine in urban regions which produced no agricultural goods. More specifically, we use historic panel data on reported production, population and death rates at the provincial level. To improve the precision of the estimates, we also investigate the relationship between famine intensity and pre-famine production, since pre-famine production is likely to be correlated with famine production. The results show that famine mortality was positively correlated to regional grain production in 1959 and production in the few years leading up to the famine although mortality is in general negatively correlated with regional grain production. To further address concerns over the quality of historical data, we supplement the provincelevel analysis with a county-level analysis using county-birth cohort level data on survival from the 1990 Population Census and the suitability for grain cultivation as predicted by natural conditions. The results are consistent with the province-level analysis. Taken literally, our estimates imply that the geographic variation in regional grain production can account for up to approximately $21 \%$ of famine severity.

Finally, we develop a model of constrained optimal policy that is consistent with these two facts. Specifically, we consider a stochastic endowment economy in which a utilitarian government is interested in equalizing food consumption across regions. The government is subject to two constraints. First, though the government knows the expected food production in a given region, it cannot verify its realization since region leaders can under-report their production in order to avoid taxation. Second, the report of income and collection of taxes in a given region occurs independently of other regions. Thus, the government is constrained in its bureaucratic capacity since it cannot condition taxes for a particular region on income reported by other regions. We consider an economy in which all regions can be affected by a binary aggregate proportional shock to food production. In this setting, optimal constrained policy assigns a constant tax or subsidy to each region. The model predicts that under the negative shock, mortality risk is sharpest in regions which produce more food since they experience a heavier tax burden. Moreover, the model predicts no rise in mortality risk for non-agricultural populations during a drop in food production since these receive constant subsidies. Finally, a counterfactual exercise suggests that the presence of free markets for food would generate lower mortality relative to the constrained optimal policy. This is because free markets incorporate the aggregate decline in food production into the price of food, resulting in a more even cross-regional decline in food consumption. ${ }^{8}$

This paper makes several contributions to the literature. First, our paper adds to existing works on the causes of famines. We show how the famine that killed more than any other can be explained by an institutional mechanism. In spirit, our study follows closely the work of Sen (1981) which argues that institutional failure can cause famine even absent aggregate food shortages. In our focus on institutional mechanisms, we complement the recent work by Burgess and Donaldson (2009) which explores the role of trade and market institutions in mitigating famines. We depart from both of these works by showing that an institutionally driven famine in a non-market economy can

${ }^{8}$ This last prediction is in line with the historical arguments made by economists such as Von Mises (1921) and Hayek (1944) who argued that a functional price system could aggregate complex information more efficiently than a small group of state bureaucrats. 
produce very different patterns of mortality through a different institutional mechanism. Importantly, the insights provided by this paper are specific to a context of a centrally planned economy such as China, the U.S.S.R., or North Korea. This is a very relevant context for studies of famines since two of the most devastating famines in history, China's Great Famine (1949-61) and the Ukrainian Famine (1932-33) occurred in such non-market economies. $^{9}$

Second, we build on existing works on the causes of China's Great Famine. ${ }^{10}$ These studies have typically focused on the drivers behind the fall in aggregate food production, whereas we take the fall in production in 1959 as given and instead focus on how institutional failures transformed this fall-which on its own could not have generated a famine-into the largest famine in history. In this endeavor, we use a rich set of newly available historic data to describe two important facts behind the famine: aggregate food production in 1959 exceeded subsistence needs, and grain production and famine severity were positively correlated across regions. We also differ from existing studies in that we attempt to provide a theory to explain the features of the famine. Interestingly, while our theory of constrained optimal policy complements existing explanations, it does not itself rely on the malevolence or misbehavior of politicians or bureaucrats. Instead, it emphasizes how imperfect information and limited bureaucratic capacity can amplify the mortality effect of a reduction in aggregate food production. To the best of our knowledge, this is a novel framework for analyzing famines.

Finally, we contribute to the recent studies in political economy on institutional capacity, and in particular, our analysis is related to the work of Besley and Persson (2009) who analyze the implications of administrative capacity on public policy. Since we focus on the role of state capacity in mitigating disasters, our work is also related to that of Cohen and Werker (2008), Kahn (2005), and Zeckhauser (1996). More specifically, we interpret state capacity in the context of the literature in public economics on optimal redistributive policy in economies with private information dating back to the seminal work of Mirrlees (1971). In contrast to this literature, we constrain the government's information processing capacity and show how this feature can lead to inefficient outcomes which fit patterns in the data. ${ }^{11}$

The paper is organized as follows. Section 2 describes the historical background for the

\footnotetext{
${ }^{9}$ It is possible that the recent famine in North Korea is also comparable in severity. However, so little is known of that famine that we forego speculations about this famine in this paper.

${ }^{10}$ See Yang (2008) for a review of the studies on the causes of China's famine. The lessons from this literature are that weather can only explain 30-50\% of the fall (Kueh, 1994; Li and Yang, 2005); and that the fall in production can be associated with many Great Leap Forward (GLF) era policies such as labor and acreage reductions in grain production (e.g., Peng, 1987; Yao, 1999), implementation of radical programs such as communal dining (e.g., Yang, 1996; Chang and Wen, 1997), reduced work incentives due to the formation of the people's communes (Perkins and Yusuf, 1984), and the denial of peasants' rights to exit from the commune (Lin, 1990).

${ }^{11}$ This literature is vast. Recent examples include Golosov, Kocherlakota, Tsyvinski (2003) and Albanesi and Sleet (2006), for instance. These studies, by assuming the government to have a rich information processing capacity, predict that the second best allocation can always be implemented via government policy, which weakly dominates competitive markets. Our framework does not allow the government to condition one agent's taxes on another agent's report and this implies a potential advantage of markets over social planning since markets serve to aggregate hidden information.
} 
famine. Section 3 describes the data. Section 4 presents the empirical evidence which is contrary to both the traditional theory as well as the conventional institutional mechanism for famine. Section 5 describes a model of constrained optimal policy which is consistent with the evidence. Section 6 concludes.

\section{Historical Background}

The Great Famine was officially called the "three years of natural disasters" (san nian zi ran zai hai). The famine began during the winter of 1959-60 and lasted until 1961. Unlike any other famine in China's history, it was not localized to one region and 17 to 30 million individuals died. This section briefly discusses the collectivization of Chinese agriculture in the 1950s, the fall in production in 1959, the grain procurement system, government control on information at the time of the famine, and how the political climate in 1959 may have reinforced the institutional mechanisms by forcing bureaucrats to follow the prescribed policies even if they were clearly problematic.

The New Communist government of China led, amongst others, by Party Chairman Mao Zedong (1949-1976) designed a centrally-planned economy similar to that of the Soviets. Some of the goals of the new government were to equalize land access between tenant farmers and landlords, rapidly industrialize, and improve military defense in case of a foreign invasion. Increasing grain output, so that urban industrial populations could be provided for, and so that national grain reserves could be replenished (after over two decades of war) was seen as a necessary ingredient for achieving these goals. Land reforms, which ultimately led to full collectivization by the late 1950s, was a means through which the government could control and improve agricultural production and distribution (Twitchett and Fairbank, 1986).

The first land reforms which redistributed land from private holders to collective ownership began in the early 1950s. Communes, which include the collectivization of all production assets, decisions, communal kitchens, grain storage, became strictly enforced in 1958 as part of the Great Leap Forward (GLF) (1958-60). Beginning in the early 1950s, the government set grain targets at the beginning of each year and procured these targets from agricultural households in rural areas after fall harvests. In theory, these targets were set so that rural households retained what they needed for subsistence (Johnson, 1998). In practice, there were accounts of local leaders procuring the target even if harvests were below what was expected and procurement left rural households with too little for subsistence. However, this did not become a widespread phenomenon and did not lead to widespread starvation until the Great Famine.

In the early 1950s, before full scaled collectivization in the GLF, peasants were able to subsist on non-grain food sources such as livestock and other crops such as sweet potatoes they planted as insurance against bad harvests. Also, before 1958, collectives mostly operated on a contract system where a complicated formula divided surplus production between the different parties. In this system, peasants retained part of the surplus production which allowed them to insure against food shortages by saving. With full scale collectivization in 1958, the government became entitled to the full surplus. Moreover, political pressure from the center caused local officials to enforce government procurement. 
In general, peasants were no longer allowed to invest labor or other inputs in production outside of what was planned by the central government. They were not allowed to store any food inside their own homes (Becker, 1996; pp.: 109). Like the Soviet collectivization during the 1930s, all livestock and draft animals became state property. Chinese peasants, like those in the USSR before collectivization, slaughtered and ate enormous quantities of meat in anticipation, reducing China's livestock by half between 1957 and $1958 .{ }^{12}$ In response to this, the Chinese government declared that slaughtering animals without permission would be considered a crime against the state and severely punished offenders. By 1959, the remaining livestock and draught animals were typically under-nourished and badly tended as peasants no longer had much interest in caring for them. This meant that by 1959, only the state could provide insurance against famine.

Since 1960, the Chinese government has alleged that a severe fall in grain output due to bad weather in 1959 caused an aggregate food shortage which resulted the famine (Coale, 1981; Yao, 1999; Peng, 1987; Ashton et al., 1984; and Banister, 1987). However, studies using historical meteorological data reported by the government and survivor recall data suggest that the weather can explain at most $50 \%$ of the variation in the fall in output in 1959 (Kueh, 1994, and Li and Yang, 2005). Moreover, the Central Meteorological Office, which by all accounts functioned accurately as a scientific monitoring station, reported that there were no abnormalities in the weather during 1959-61 and that it was actually rather good. In previous versions of this paper, we have verified these claims using the recently released historical data from China's permanent weather stations. ${ }^{13}$

There are several more plausible alternative hypotheses for the cause in the fall of output in 1959. First is the hypothesis that, in an effort to meet unrealistic production targets, farmers employed methods that yielded high output in the short run but were not sustainable in the long run. Anecdotal accounts recall that weather conditions in general had been particularly good in those years. Communes also practiced methods such as close cropping (e.g. the Lysenko Method), slash-and-burn and double (and sometimes triple or even quadruple) cropping when first collectivized in order to produce high yields. Such methods inevitably wore out the soil and had detrimental effects on long run production (Becker, 1996; pp. 102). Concerns for reduced long run yields were most likely overcome by immediate political pressure to meet targets. Second, diversion of labor away from agriculture for GLF projects may have decreased production in 1959 (Li and Yang, 2005).

In 1959, a year of reportedly normal weather conditions, production fell by approximately 30 million tons (13\% from 1958). However, procurement increased by over $20 \%$ from 52 million tons in 1958 to 64 million tons in 1959. People began to die of starvation in large numbers during the winter of 1959 and the highest levels of mortality occurred in January and February of 1960. Those who survived had little physical strength to work in 1960. The lack of labor input was exacerbated by the fact that other inputs such as draught animals, seeds, and even organic fertilizers had been consumed by starving peasants. The strict and largely successful restriction on migration prevented farmers

\footnotetext{
${ }^{12}$ See Yang (2008) for a comparison of the famines in China and the USSR.

${ }^{13}$ These results are omitted due to space constraints and are available upon request. Becker (1996) establishes this using interview with officials of the Chinese Meteorological Centre. Until recently, access to the agency's reports were limited to senior members of the communist party (Becker, 1996, pp. 268).
} 
from any type of informal cross-regional insurance. The famine ended in 1961, when the army to delivered grain and clothing from government reserves to the countryside. Grain production gradually recovered in the following few years.

Table 1 shows the historical aggregate production and procurement data provided by Li and Yang (2005). Their data are a retrospectively corrected historical series released by the Ministry of Agriculture in 1989. Their sample contains 21 provinces. We plot the production from column (1) in Figure 4A. It shows that production was increasing slowly during 1952-55. The following three years, 1956-58, experienced bumper harvests, where production increased from approximately 170 million tons to approximately 200 million tons. In 1959, production decreased to 1955 levels. Two facts follow from this figure. First, food production during the first year of the famine was still higher than the average of 1952-55, when there was no famine. Second, China experienced a monotonic increase in food output prior to the famine, during 1952-58. This is shown more clearly in columns (2) and (3) where we calculate the per annum and four year moving averages of growth rates in grain production. They show that prior to the famine, national grain production grew at approximately $4 \%$ per annum on average.

Figure 4B plots grain procurement in levels and as a percentage of production that is surplus to the needs of laborers (see Table 1 Columns (6) and (7)). ${ }^{14}$ It shows that procurement increased during 1952-54 from approximately 33 million tons (85\% of surplus production) to 50 million tons (114\% of surplus production). In 1959, procurement increased to 64 million tons. The high procurement levels combined with the fall in grain output meant that procurement had increased to $143 \%$ as a percentage of surplus production. In 1960-61, the last two years of the famine, the further fall in production levels meant that procurement as a fraction of total production increased further even though procurement levels had decreased. Note that procurement rates remained stable at approximately 33\% throughout the rest of the 1960s and 70s. Figure 4C plots per capita grain retention and aggregate retention as a fraction of production from Columns (4) and (5) of Table $1 .{ }^{15}$ The solid line shows that grain retention per person decreased

\footnotetext{
${ }^{14}$ We define surplus production as the difference between total production and the level necessary for subsistence. For the latter, we conservatively use the minimum in retention levels during the years before the famine. It is $228 \mathrm{~kg}$ per person in 1952 . This amount provides roughly 2,240 calories per day, more than the 2,100 calorie per person per day minimum nutrition requirement for agricultural workers prescribed by China's Institute of Nutrition and Food Hygiene (INFH). To translate this to aggregate retention levels, we multiply this by the number of individuals in their sample, approximately 549 million
} individuals.

$$
\text { Procurement_Share }_{t}=\frac{\text { Procurement }_{t}}{\text { Production }- \text { retention_percapita } \times \text { total_pop }}
$$

${ }^{15}$ We calculate aggregate retention by multiplying the per capita retention by the population of the provinces in the sample (approximately 547 million individuals). We then convert the unit from kilograms to millions of tons. We divide this measure of retention by total production from Column (1) to obtain retention as a share of production.

$$
\text { share_retained }=\frac{\text { retention_pc } \times \text { total_population }}{\text { total_production }}
$$


from approximately $260 \mathrm{~kg}$ per person (87\% of production) in 1952 to approximately 228 $\mathrm{kg}$ per person ( $74 \%$ of production) in 1954 . It increased to a peak of $284 \mathrm{~kg}$ per person ( $81 \%$ of production) in 1956. It then began to decline. In 1959, only $193 \mathrm{~kg}$ per person (62\% of production) was retained. Retained grains fell further to $182 \mathrm{~kg}$ per person in 1960 although as a share of production, it had increased to $70 \%$. Based on the food content table provided by the Institute of Nutrition and Food Hygiene of China, one kilogram of grain (simple average of rice, wheat flour, and other grain) provides approximately 3,587 calories. $182 \mathrm{~kg}$ will provide a diet of approximately 1,789 calories per day, which is only $85 \%$ of the 2,100 calorie per person per day minimum nutrition requirement. This is broadly consistent with Ashton et al.'s (1984) finding that daily food intake fell to as low as 1,500 calories per day by 1960 .

The famine was mostly felt by agricultural areas. Non-agricultural areas (e.g. towns and cities) were provided with grain subsidies by the government. While there were accounts of malnutrition and starvation in cities from reduced food rations in 1960-61, the magnitude is relatively small compared to the country side. In fact, most urban residents had little idea of the true extent of the famine.

The political climate in 1959 most likely made leaders very reluctant to admit a production shortfall that autumn after harvests had been realized. In July that year, Mao had famously purged Peng Dehuai, a field marshal of extremely high political standing, for criticizing collectivization and other GLF policies and expressing forebodings of famine. ${ }^{16}$ The Lushan conference had important consequences. The removal of Peng was accompanied by a violent purge of all of his supporters amongst top party members as well as any moderate mid-level party leaders who had expressed concerns about collectivization and the dangers of famine (Becker, 1996, pp. 93). It put remaining leaders under enormous pressure to deliver the high targets for grain quotas for the harvest of 1959 in order to not be grouped with the critics of Mao.

Lushan pressured local leaders to fulfill their procurement target even in the event of a production shortfall, and central leaders to be hesitant in admitting the aggregate shortfall as they heard increasing number of reports from their field officers. Given that one of the communist party promises was to insure against famine and that weather conditions in 1959 was not remarkably bad, local leaders may have simply decided to be absolved from responsibility and follow the rules literally under the assumption that grains necessary for

\footnotetext{
${ }^{16}$ These problems of the collective system mandated by the GLF were a source of contention between communist party moderates and hardliners who backed Mao. However, with the exception of Peng Dehuai, a field marshal who did a tour of the countryside during the spring of 1959, there is no evidence that any top leader ever obtained an accurate picture of the problems collectivization and the danger of famine. Peng discretely reported these problems to Communist Party Chairman Mao Zedong in a personal letter. The problems he mentioned included reduced incentives to work, a diversion of labor away from agriculture and over-procurement of grain by mid-level party leaders who were under-pressure to fulfill grain target quotas that had been set too high. Fearing a political revolt against his leadership based on perceived failures of the GLF, Mao used the contents of this letter to purge Peng as a rightist at the historic Lushan conference in July of 1959. The latter was put under house arrest and later executed during the Cultural Revolution. At this conference, the top party leaders made clear that the first year of the GLF was a success and that collectivization was increasing grain harvest more than ever (Becker, 1996, pp. 87-92).
} 
subsistence will be returned when the retained stores run out. ${ }^{17}$ The same central pressure will of course also have caused the procurers to be reluctant to disappoint targets. The result was that in the time between when local rural grain stores ran out, and when the replenishments were reluctantly made in 1961, 17-30 million people died. ${ }^{18}$

Unlike any famine other than the Ukrainian Famine (1932-33), population from famine stricken regions were not allowed to migrate away. This rule was mainly in place to prevent information of the severity of famine to spread and cause political unrest. ${ }^{19}$ This means that famine severity varied substantially, even across neighboring regions. This should become immediately obvious when comparing the average daily caloric intake of 1,500-1,789 in 1959 that we described earlier, which is the average across populations that suffered varying degrees of famine, and the necessary caloric requirement for staying alive, which is only around 900 calories for an adult (Dasgupta and Ray, 1986). If food was distributed equally across China, then there should have been no mortality.

The geographic inequality in severity, one of the key facts that this study tries to explain, is a topic that has not been paid much attention in studies of China's famine. Our study takes both the political climate of the GLF era and the fall in production in 1959 as given and will focus on explaining how in that context, the institutions at the time transformed that fall into a famine that killed approximately $7 \%$ of the rural population at the time on average, and over 50\% in many regions (See Figure 6B, a histogram of famine severity across counties measured in terms of survival in 1990).

\footnotetext{
${ }^{17}$ There is little doubt that the near certainty of being punished for not meeting production targets must have weighed heavily against those who considered delivering less grain in fear of famine. However, it is interesting to note that one of the promises of the communist government was that no one in China would ever suffer from famine again. Therefore, it is possible that local leaders and farmers may have assumed that they will be replenished once their retained grain stores were depleted. By postponing the plea for grain from the central government, local leaders could postpone their own punishments. This is consistent with accounts of collective kitchens providing large quantities of food even after the smaller fall harvests were realized (e.g., Yang, 1996; Chang and Wen, 1997). The rigidity of rules and how it caused officials to sacrifice efficiency can be observed in food delivery. Oi (1999) documents that local leaders punctually put harvests by the roadside for pick up even in bad weather causing huge losses sometimes. Presumably, these leaders knew that they would be punished for the lack of punctual delivery but not for bad weather induced losses. Local leaders may have had an additional sense of false security from believing that the decrease in production was not shared by other regions. During the late 1950s, there was a general belief that China was awash with food. This belief came from government propaganda and the unusually high yields in the years before the famine. In the fall of 1958, villagers were explicitly encouraged to eat as much as they wanted from communal kitchens (Becker, 1996, pp. 80). Pressure to not publicize shortfalls and the strict control on information flows would prevent collectives from knowing about the general decrease in production in 1959.

${ }^{18}$ Collectivization may have also delayed peasants' realization of the danger of famine until it was too late to revolt. For example, harvests from individual farmers were pooled and stored in a communal warehouse. This decreased the accuracy of farmers' information on the amount of grain they produced or the amount of grain that is procured.

${ }^{19}$ Travel was controlled by rationed tickets and the need to apply for permission to leave one's commune. Party officials were ordered to arrest all travellers and to not provide food or shelter for refugees (Becker, 1998, pp. 128). In cities, the lack of information was exacerbated during the famine when the number of flights and passenger train departures were cut in half (Becker, 1996, pp. 95).
} 


\section{Data}

This study uses food production and demographic data from several sources. The national and province level historical data on grain production are based on a series published by the National Bureau of Statistics (NBS) in 1999. In addition, we proxy for the otherwise unavailable historical county-level production with data on the county-level suitability for grain cultivation as predicted by natural conditions using a model and data provided by the United Nations Food and Agriculture Organization's (FAO) Global Agro-Ecological Zones (GAEZ), 2002 database. The national historical data on population and deaths are based on a re-constructed series recently released by the China Population Information and Research Center (CPIRC) in 2000. ${ }^{20}$ The province level data on historical population and death rates comes from the Comprehensive Statistical Data and Materials on 50 years of New China published by the China Statistical Press in 1999. In addition, we proxy for the otherwise unavailable historical county-level famine severity measures such as population and mortality rates with birth cohort size in the 1990 Population Census.

There are two main issues to keep in mind in our analysis of each of the provincial-level series. The first issue regards accuracy. The national and provincial food production and demographic data have been corrected retrospectively to account for contemporaneous reporting errors. ${ }^{21}$ For our study, the main concern is that the official national figures overstate actual production and understate actual population. This would lead us to incorrectly overestimate available food per capita in 1959. In principle, this should not be the case since these data were reconstructed precisely to address issues related to historical misreporting. ${ }^{22}$ A comparison of contemporaneous reports of grain production and the reconstructed data suggests that the production numbers have been drastically revised downwards. For example, the People's Daily in August 1, 1958, claimed that "Rice production exceeded $7500 \mathrm{~kg}$ per mu (0.067 hectare)" for a county in Hubei province. The revised statistics report that actual grain output in that province was closer to being $120 \mathrm{~kg}$ per mu. In fact, a comparison of the national aggregate of our production data for 30 provinces in Table 2 Column (1) to the data aggregated over 21 provinces reported by Li and Yang (2005) in Column (1) shows that our production data is approximately $10 \%$ less than their data, which was reported by the government ten years prior to the reporting of our data. This suggests that in the last decade or so, the Chinese government has made a continued effort to retrospectively correct for past over-reporting of production. In our analysis, we will use the new and lower production estimates in Column (8) to be conservative.

The second issue regards the completeness of the province level data. The grain production numbers in our data are based on the same original data as the series reported

\footnotetext{
${ }^{20}$ See http://www.cpirc.org.cn/en/totpope.htm

${ }^{21}$ The only exception to this is the province level data on historical population which should be interpreted with extra caution since these are contemporaneously reported and not retrospectively corrected for reporting errors.

${ }^{22}$ Moreover, to the extent that the current government which reports these statics is biased, it would likely be biased in the direction of under-reporting production and over-reporting population so as to preserve the 1959 government's claim of the existence of an aggregate food shortage below per capita subsistence needs.
} 
by the Ministry of Agriculture in 1989 used in the study by Li and Yang (2005). However, as we mentioned above, the production numbers have been further revised downwards and provinces for which production could not be accurately revised (Sichuan) has been dropped from the sample. ${ }^{23}$ Therefore, the production data used in this paper will be the most conservative data ever used in a study of the Chinese famine. Similarly, mortality data are not available for the year 1959 for three provinces: Tibet, Hainan and Sichuan. Li and Yang (2005) addressed this by using data only from 21 provinces. In this study, we use all the available data as the particular omissions most likely bias against the point made by this study: that there was no aggregate shortage in 1959. See the next section for a more detailed discussion.

We plot the death rates over time for each province in Figure 5A. This figure shows that there is substantial variation in famine death rates, and that death rates peaked in 1960. One striking observation is that there was no change in mortality rates in any of the three urban municipalities (Beijing, Shanghai and Tianjin) during the famine and that most of the mortality occurred in rural provinces.

Table 3 Panel A desribes the province level data. It shows that a province had on average a population of 20 million over the period of 1949-76. Average mortality rate was approximately 12 per 1,000 individuals. During the famine years when mortality was highest, 1959 and 1960, mortality was almost double the average at approximately 21 per 1,000. On average, each province produced approximately 54 MT of grain per year. Grain includes all cereals. In the four years leading up to the famine, production was slightly higher than average at approximately 55 MT per province. In 1959, the first year fo the famine, production was approximately $53 \mathrm{MT}$ per province. Measured in per capita terms, average grain production was approximately $289 \mathrm{~kg} /$ person on average. In 1959, it was approximately $252 \mathrm{~kg} /$ person. ( Reacall that in 1959, grain production was not reported for Sichuan, which on average has three times the population and produces three times as much as grain as other provinces on average. Also, mortality is not reported for Sichuan, Tibet and Hainan in 1959).

Given the limitations of the available historical data, we conduct a county-level analysis by constructing a county-level panel of survival by birth cohort and county to serve as a robustness check for our conclusions. This has several advantages. First, we avoid reporting biases in the historical data by using proxies for production and famine severity measured decades after the fact. Second, this allows for a more disaggregated analysis and for more variation in the data. Third, this allows us to analyze agricultural and non-agricultural populations separately. Nevertheless, our construction of the data comes with the caveat that our data is at best a proxy for the actual county-level production and population figures.

The county-level sample is constructed as follows. We proxy for historical production at the county level with data on suitability for grain cultivation as predicted by natural conditions from the FAO. ${ }^{24}$ Their measure of suitability is based purely on the biophysical

\footnotetext{
${ }^{23}$ In non-famine years, Sichuan produces approximately three times the grain as the average province, and its population is similarly thre times that of the average province.

${ }^{24}$ The data are the result of over twenty years of research and are the product of a joint collaboration between the FAO and the International Institute for Applied Systems Analysis (IIASA).
} 
environment of a region and it is not influenced by which crops were actually adopted in an area. Factors that are easily affected by human actions, such as soil $\mathrm{pH}$, are not parameters in their model. ${ }^{25}$ The data on suitability is available at a $50 \mathrm{~km} \times 50 \mathrm{~km}$ grid cell level, where one can choose the level of agricultural inputs on which to base the calculation. Our chosen level of inputs allows for rain-fed irrigation but no heavy machinery or chemical fertilizers since GLF policies forbade chemical fertilizers and since the use of heavy machinery such as tractors would have been unlikely in this era. We aggregate grid-level data to the county data as follows. The grid level data reports the predicted amount of output of rice and wheat. If a grid can produce $40 \%$ or more of the maximum possible output for any grid, then we code it as "suitable". The suitability measure at the county level is the fraction of grids within a county that is suitable. We use this measure for the sake of computational ease. ${ }^{26}$ Since procurement targets treated rice and wheat similarly, our measure of suitability is the union of land that is suitable for either rice or wheat within each county. To get a sense of the county-level agricultural suitability data, Appendix Figures A1A and A1B present maps that overlay county level boundaries with the grid level suitability measures for rice and wheat, respectively. Table 2 shows that on average, $14-15 \%$ of land is suitable for cultivating rice or wheat.

For the county-level measures of famine severity, we use survival. We proxy for survival with the cohort size in the 1990 Population Census. Smaller cohort sizes reflect lower survival (and lower fertility) due to more intense famines. This relationship should be especially strong for individuals who were very young or elderly at the time of the famine, since the young and the elderly are biologically more vulnerable to health shocks. ${ }^{27}$ Because the elderly from 1959 would generally not be alive in 1990, our study focuses on individuals who were born during the famine. We use data from the sample from the 1990 China Population Census. Because the famine was mainly a rural phenomenon, we exclude cities. For each county, we divide our sample into agricultural and non-agricultural households. This is an official government classification that is unlikely to have changed between the famine era and 1990. We further restrict our sample to individuals who report as having lived in the same county for over five years, and in doing so exclude less $5 \%$ of the sample. Note that because strict migration policies made it extremely difficult for rural individuals to move, we interpret our sample as people who are living in their county of birth. ${ }^{28}$ We aggregate the data into birth year and birth county cells for agricultural and non-agricultural households.

The result from our county-level data construction is a balanced panel of 1,454 counties

\footnotetext{
${ }^{25}$ Nunn and Qian (2009) provide a detailed description of the construction of this data and how to calculate suitability measures at the regional level from this data. We follow their method.

${ }^{26}$ Moderately changing the threshold will not affect the estimates.

${ }^{27}$ Moreover, during famines, a household may also concentrate its food supplies on prime age adults who can work to bring in income and food.

${ }^{28}$ Another potential concern is that cohort size in 1990 may not accurately measure regional survival form 1959 because of migration. We think this is unlikely to be problematic because internal migration controls were well enforced between when the famine occurred and 1990. Nonetheless, some rural regions at the time of the Census may have comprised urban youths who moved from cities to rural areas during the Cultural Revolution (1966-76), a factor which would cause us to under-estimate famine severity in rural regions. See Qian (2008) for a discussion of migration in using the 1990 China Population Census.
} 
and 36 birth years for agricultural households, and 1,414 counties and 36 birth years for non-agricultural households. The latter is smaller because not all counties have nonagricultural populations. Table 3 Panel B describes the county-level data. It shows that agricultural households have approximately 3,714 individuals per cohort on average in each county. Famine cohorts are smaller on average, comprising of approximately 3,301 individuals. This is approximately $28 \%$ smaller than the cohorts born prior to the famine (1954-57), which contain approximately 4,968 individuals per county. The ratio of the famine cohort relative to the pre-famine cohort is approximately 0.72 . If we use this ratio being below one to indicate whether there was a famine, then $85 \%$ of the counties in our sample experienced a famine. The table also shows that famine was more severe for agricultural households than non-agricultural households living in the same county. The ratio of famine cohort to pre-famine cohort is larger in non-agricultural households (0.85) than agricultural households (0.72). Moreover, $85 \%$ of counties comprised agricultural households that experienced some famine. In comparison, only $65 \%$ of counties comprised non-agricultural households that experienced some famine.

Figure 6A aggregates the county-level survival data to the national and birth year level, and plots the number of people living from each birth year for agricultural and nonagricultural households. It shows that both agricultural and non-agricultural households experienced a decrease in cohort size close to the famine years, thoug the drop is much more dramatic for the agricultural population. The figure projects a linear trend for the agricultural households and shows that there is a positive linear trend in cohort sizes from 1942 to approximately 1955. Cohort sizes are well below trend for individuals born right before and during the famine as indicated by the vertical lines, though they return to trend after 1961 when the famine is over. Figure 6A shows that the cohort size is smallest for individuals born during the famine (1959-61). To observe the cross sectional variation in famine intensity, we plot a histogram of the ratio of famine cohort size to pre-famine cohort size for agricultural and non-agricultural populations in Figure 6B. These show that there is substantial cross sectional variation in famine intensity; and that non-agricultural households suffered much less.

One should keep some important issues in mind in using the survival data measured in 1990 to supplement the province-level historic data on population and mortality. As a comparison, Figure 5A plots province mortality rate over time and Figure 5B plots province birth cohort size over time. Though the patterns across provinces are generally consistent, many provinces do not exhibit high mortality rates but exhibit large declines in cohort sizes. The survival data is not biased by the government's under-reporting of famine era mortality. Therefore, as a measure of regional famine intensity, it is more accurate than province level mortality data. However, survival will measure of famine mortality with noise because it also captures a reduction in fertility caused by the famine, and it ignores the mortality of any children who were born during pre-famine fertility booms, which would imply that the survival data understates mortality. This latter point is not very important for this study, which only uses mortality to infer famine intensity.

Note that one piece of evidence which is not available for our analysis is regional data on historical procurement. Our extensive investigations into publicly available archives together with interviews of past and current government officials suggest that such data 
no longer exists. Nonetheless, Ministry officials claim that the method for procurement has not changed much since the centrally planned procurement system was established in the early 1950s. In light of this fact, we analyze more recent annual province level data on procurement targets from 1980-88. Though the exact formula for setting procurement targets is not publicly available, we impute it by analyzing this data in conjunction with province-level data on grain output in 1980-88 from the National Bureau of Statistics (NBS) to estimate the elasticity of procurement targets with respect to past per capita surplus production. Using this imputed formula, we can establish some facts which help to interpret the mortality data and which are consistent with our theoretical model.

\section{Empirical Evidence}

This section presents two sets of empirical evidence. First, we show that although there was a fall in national food production in China in 1959, there was no food shortage in terms of aggregate subsistence needs. In highlighting this fact, we also show using historical province-level data that the percentage reduction in food production was approximately evenly distributed across regions, an observation which will be later useful for our theoretical model. This leads us to conclude that the famine was institutionally driven. Second, we show that-in contrast to the predictions of the conventional institutional mechanism of famines-regions that produced more grain in 1959 suffered higher mortality rates in the following winter. This means that the famine was driven by a different institutional mechanism than the one described by Sen (1981), an issue which we explore in detail in Section 5.

\subsection{National Grain Production and Subsistence in 1959}

The traditional theory of famines predict that China's famine must be the consequence of a food shortage below per-capita subsistence needs. In this section, we compare the historical estimates of national food production to two benchmarks for caloric needs in 1959, and we show that the evidence is inconsistent with the traditional theory of famine. The two benchmarks distinguish between the caloric needs for preventing starvation, from the needs for preventing mortality. It would not be a priori surprising to find that production in 1959 did not fall below the latter since aggregate production in 1959 only dropped to the same level as in 1956, when there was no known incidence of famine.

Our first benchmark is based the amount of food needed for adult laborers to be productive in agriculture. We use a diet of roughly 2,240 calories per day, which is the level implied by the lowest per capita retention in the years before the famine (see Table 1). (This is similar to the recommended diet by the Ministry of Health in China is 2,100 calories per day). If per capita caloric availability falls below this level, then there will be starvation. We assume that the entire population is made of prime age laborers. In reality, a large proportion of the population will be comprised of children or the elderly, who need fewer calories to subsist. Lacking historical data on the age distribution by region, we have made the conservative and extreme assumption that the entire population are those that need the most calories, and thereby grossly over-estimating caloric needs. Table 2 
Columns (1)-(3) show the historical aggregate production, population, and aggregate food needs according to the 2,240 calorie per day level. Column (4) is the difference between aggregate production and subsistence needs. It shows that relative to this need, there was a 5 million ton deficit in production in 1959. Therefore, there may be starvation and malnutrition. This is illustrated in Figure 1, which plots aggregate production and subsistence needs over time. Note, however, that the magnitude of the deficit is less than those in 1949-50, when there were no accounts of famine.

Our second benchmark is based on the amount of calories needed for survival, which is approximately 900 calories per adult per day (Das Gupta and Ray, 1986). Columns (5) and (6) in Table 2 show that in 1959, there was approximately 87 million tons of grain surplus to what was needed to prevent mortality due to famine. This is also illustrated in Figure 1.

It is not difficult to imagine reasons that would cause these data on production and population to be inaccurate. But these calculations, as illustrated in Figure 1, show that it is almost impossible that production in 1959 was too low to provide the diet of 900 calories a day that would have prevented mortality. In other words, the main point conveyed here, that the fall in production by itself could not have caused the famine must be true unless if our data on production in 1959, the most conservative that has been used in any study of the famine, still overstates true production by over $41 \%$. This seems highly unlikely. Moreover, our estimates for caloric needs overstates actual needs because for two reasons. First, because of the data availability issues described in the previous section, national grain production data excludes Sichuan, a major grain producing province that in normal years produce three times the grain as the average province, where as the national population data includes all thirty provinces. ${ }^{29}$ Therefore, we under-estimate grain production per capita on average. Second, lacking data on the age distribution of past years, we have assumed that the entire population is made up of adult laborers. If we take this overstatement of aggregate caloric need into account, it means that even falling below the necessary level to avoid starvation is probably highly unlikely.

In addition to the key fact above, we can use the provincial historical production data to examine whether the fall in production in 1959 was proportional to the past production of each region. Figure 3A plots the fall in production in 1959 as a fraction of past production against average annual past production. It shows that there was an aggregate proportional fall in 1959 and provinces that produced more per capita in the past did not seem to suffer larger percentage reductions on average. This is illustrated more clearly in the residual plot of the bivariate regression of the percentage fall in per capita grain production in 1959 and annual per capita grain production during 1954-58 shown in Figure 3B. This is an important stylized fact to keep in mind for our construction of the theoretical model.

\footnotetext{
${ }^{29}$ Because the restrospectively corrected population data reported by the CPIRC is only reported at the national aggregate level, we cannot substract an accurate measure of population of Sichuan out of the aggregate numbers for 1959 .
} 


\subsection{Regional Grain Production and Famine in 1959}

The results from the previous section suggest that the famine must have had an institutional cause. The understanding of the institutional mechanism for famine due to Sen (1981) is that institutional failure makes low food production regions incapable of acquiring food from high food production regions, leading to famine in the low food production regions. This implies a negative cross-regional correlation between food production and famine intensity. In this section, we show that, not only is this correlation not present in the Chinese data, but that the exact opposite correlation holds with high food production regions experiencing a higher famine intensity.

In the previous section, we examined the time series pattern in production. Here, we examine the cross sectional relationship of famine severity and grain production in 1959. Table 2 Column (7) lists the provinces in ascending order of 1960 mortality rates (shown in Column (8)). Column (9) shows per capita grain production for each province. ${ }^{30}$ Columns (10) and (11) calculates the production deficit relative to the two benchmarks described above. A striking pattern emerges. The provinces with the largest production deficits are also the provinces that suffered the least mortality in 1959. In fact, the three urban municipalities, Beijing, Shanghai and Tianjin, which produce less grain per capita than other regions, suffered very little famine induced excess mortality.

This pattern can be better illustrated by plotting the natural logarithm of mortality rates against the natural logarithm of per capita grain production in 1959. Figure 2A shows that there is a strong positive correlation. Figure $2 \mathrm{~B}$ plots the residuals from the bivariate regression of the natural logarithm of the 1960 mortality rate and the natural logarithm of grain production in 1959. We estimate a simple bivariate correlation between the natural logarithm of the mortality rate in 1960 for province $p$ and the natural logarithm of grain production in 1959 for province $p$.

$$
\ln \left(\text { death }_{p}\right)=\beta \ln \left(\text { grain } 1959_{p}\right)+\varepsilon_{p}
$$

It shows a strong positive correlation between grain production in 1959 and mortality rates. The estimated coefficient, $\beta$, is approximately 0.14 , suggesting that provinces which produced more grain also experienced higher mortality, which is counter to the understood institutional mechanism for famine. ${ }^{31}$ The estimate is statistically signficant at the $10 \%$ level.

Interestingly, the positive correlation between grain production and famine severity is only true for the famine years. In Table 4, Columns (1)-(4), we show the estimated coefficient for the correlation between grain produced in a given province and given year with population and mortality. Columns (1) and (3) show that for the years before the

\footnotetext{
${ }^{30}$ For mortality, we use the sum of deaths from 1959 and 1960. This is because mortality is reported for each calendar year and much of the deaths that occured in the winter following the 1959 harvest were during January, February and March of 1960.

${ }^{31}$ As discussed in Section 3, according to most scholars of the famine, these mortality data understate true mortality from the famine, since officials at the time of the famine were under pressure to repress mortality rates. Nevertheless, there are no accounts of systematically biasing the death count across regions. Therefore, these data should be able to serve the purpose of illustrating the cross-sectional trend between production in 1959 and mortality rates.
} 
famine, 1949-58, and after the famine, 1961-66, grain production is positively correlated with population and negatively correlated with mortality. This is not surprising since one would a priori expect that increased food consumption would increase fertility as well as decrease mortality by decreasing morbidity, both of which would lead to increases in the observed population. In contrast, columns (2) and (4) show that for the three famine years, this is not true. This is an important point to keep in mind when we consider the implications of our model in the next section.

To improve the precision of the estimates, we exploit the panel structure of the province level data on production and mortality. We estimate the following relationship.

$$
Y_{p t}=\beta\left(\ln \left(\text { grain } 1959_{p}\right) \times 1960 d u m m y_{t}\right)+\gamma_{t}+\delta_{p}+\alpha X_{t p}+\varepsilon_{p t}
$$

The outcome (total population or the number of deaths) in province $p$ and year $t$, $Y_{p t}$, is a function of the following variations: the interaction term between the natural logarithm of grain that is produced in that province in 1959, $\ln \left(\right.$ grain $\left.1959_{p}\right)$, and a dummy variable for 1960, 1960dummy $y_{t}$; a vector of province and time varying controls, $X_{t p}$; province fixed effects, $\delta_{p}$; and year fixed effects, $\gamma_{t}$. Province fixed effects control for all time-invariant differences across regions. Year fixed effects control for all changes over time that affects all regions similarly. In some regressions we also add additional controls such as province-specific year time trends, public spending on agriculture, public spending on health, education, and science, and the number of primary and secondary school teachers. These additions attempt to control for other factors which may affect mortality rates. Note that the positive correlation between grain production in 1959 and mortality in the winter of 1959/60 implies a coefficient of $\beta<0$ for the effect on total population and a coefficient of $\beta>0$ for the effect on the number of deaths.

The estimates are shown in Table 4. Column (5) shows that a province that cultivated 1\% more grain in 1959 on average suffered an $8 \%$ larger loss in total population. Column (6) shows that adding the additional controls reduces the magnitude of the coefficient slightly, but it is statistically similar to the basic estimate without controls. Both estimates are statistically significant at the $1 \%$ level. Columns (7) and (8) show that the effect on the mortality rates are very similar in magnitude. However, they are not statistically significant. This is most likely due to measurement error in the mortality data.

Since production is correlated over time for each region, one should find a similar pattern between historic regional production (e.g. production in the years prior to the famine) and famine severity. In columns (9)-(12), we repeat the same estimation except the independent variable is now the interaction term between the average annual grain production during 1954-58 and a dummy for 1960. The estimated effect for total population deaths and their significance levels is similar to the estimate in columns (5)-(8).

As we described in Section 3, there are many concerns over the quality of the province level data on historic population and production. To address this issue, we conduct a supplementary analysis at the county level using survival data as measured by birth cohort size from the 1990 Population Census and a proxy for grain production measured as the suitability for cultivating rice or wheat as predicted by time-invariant natural conditions. As we discussed in Section 3, the survival data will likely understate the level famine mortality because it will not be able to measure the death of those who 
were elderly at the time of the famine. However, as long as the deaths of the elderly as a proportion of total county population does not vary according the the amount of grain cultivation, this does not pose a serious problem for the regression estimates. This supplementary analysis has three major advantages over the province-level analysis. First, the disaggregated nature of the data allows us to capture much more of the variation in famine. Second, the survival data from the 1990 Population Census can be divided into agricultural households who were subject to grain taxation by the central government, and non-agricultural households who were not taxed and in contrast received grain subsidies. Finally, and most importantly, the data quality is much better than the historic data since it is not subject to concerns of misreporting. Therefore, the supplementary analysis can be viewed as a robustness check for the provincial historic analysis.

The county-level panel divides individuals from the 1990 Population Census into agricultural and non-agricultural households, and it aggregates them into birth-year and birthcounty cells. We estimate the effect of the capacity for grain cultivation on 1960 birth cohort size separately for agricultural and non-agricultural households.

The estimating equation for the county-level analysis is the same as equation (4), except now we control for county fixed effects instead of province fixed effects and birth year fixed effects instead of calendar year fixed effects. This compares birth cohort sizes across areas that suffered varying levels of famine severity, between cohorts born during the famine and those born before and after. This implicitly assumes that there is a secular trend in cohort sizes over time absent the famine, and infers famine intensity by seeing how much the famine cohort size falls below that trend. ${ }^{32}$

Table 5 Column (1) and (2) consider agricultural households. Column (1) shows that a county which is $100 \%$ suitable for producing grains had birth cohort sizes that were $24 \%$ smaller in 1960 . The estimate is statistically significant at the $1 \%$ level. Column (2) shows that this estimate is robust to the inclusion of province-year fixed effects; it is twice as large in magnitude and also significant at the $1 \%$ level. To interpret these estimates, note that on average, approximately $14 \%$ of land across counties are suitable. The average effect is the product of the mean suitability and the estimated coefficient. Therefore, on average, suitability for grain production is associated with a decrease in cohort sizes by 3.5-7\% for agricultural households. Since the 1960 cohort for agricultural households was on average 34\% smaller than earlier cohorts, this estimate, taken literally, suggests that the variation in grain production can explain approximately $10-21 \%$ of the decrease in cohort size of agricultural households due to the famine. Since most of the famine was felt by agricultural households, the effect on agricultural households effectively reflects the effect on the overall famine.

In Columns (3) and (4), we repeat the estimation for birth cohort sizes of nonagricultural households. The estimated effects show that for these households, local grain cultivation is not correlated with 1960 birth cohort size and the coefficient is statistically

\footnotetext{
${ }^{32}$ Hence, our measure could understate the true severity of famine. If regions that experienced severe famines also experienced above average fertility rates in the years before the famine, and those "extra" children all died during the famine, then a comparison of famine birth cohort size and pre-famine birth cohort size will understate the cohort size reduction due to the famine. This will cause our estimate of the correlation between grain production and famine severity to be attenuated.
} 
insignificant. This means that non-agricultural households with proximity to food did not experience systematically higher or lower mortality than other regions. Thus, the positive correlation between food production and mortality is confined to the agricultural households which were subject to procurement by the government.

To illustrate to effect of being born in a grain producing region across birth cohorts more systematically, we estimate the effect of grain suitability for each birth year separately as in the following equation. For this exercise, cohorts born before 1943 are collapsed into one reference group.

$$
\ln \left(\text { cohortsize }_{i t}\right)=\sum_{s=1943}^{1966} \beta_{s}\left(\text { grain_suit }_{i} \times \text { biryr }_{s t}\right)+\alpha+\gamma_{i}+\delta_{t}+\varepsilon_{i t}
$$

The natural logarithm of the cohort size of individuals born in year $t$ in county $i$, $\ln \left(\right.$ cohortsize $\left._{i t}\right)$, is a function of the following variables: the interaction terms between the fraction of land that is suitable for rice or wheat production in county $i$, grain_suit $_{i}$

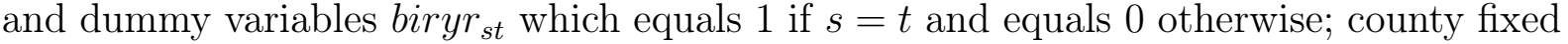
effects, $\gamma_{i}$; and birth year fixed effects, $\delta_{t}$. The reference group is comprised of individuals born during 1930-1942. This group and all of its interaction terms dropped. All standard errors are clustered at the county level. The inclusion of year fixed effects controls for secular changes in fertility and mortality that may affect cohort sizes. The inclusion of county fixed effects controls for time-invariant differences between counties. For example, counties that are more suitable for grain cultivation are also typically richer and provide better health care, and this may cause these counties to have larger cohorts or more resilient to negative shocks. Note that given our results thus far, we should expect that for agricultural households $\beta_{t}$ should not be statistically different from zero for individuals born after the famine, $t>1961$. As Figure 6 suggests, most of the reduction in cohort size occurs for individuals born during 1959-1961. Our analysis thus predicts that $\beta_{t}$ should be negative for those years so that the cross-regional reduction in cohort size is negatively correlated with grain suitability in these years.

This prediction is validated in the estimates which are presented in Appendix Table 1 Column (1). The coefficients and their $95 \%$ confidence intervals are plotted in Figure 7A. It shows that suitability for grain is negatively correlated with cohort size for those born right before and during the famine, and has no effect for those born after the famine. Note that grain suitability is actually positively correlated with cohort size for those born many years before the famine, an important issue to keep in mind our analysis of the theoretical model.

Next, we estimate the same equation for the sample of non-agricultural households. The coefficients are shown in Appendix Table 1 Column (2). They are plotted in Figure 7B together with the estimated coefficients for agricultural households. The figure shows that for cohorts born many years before the famine and after the famine, the correlation between cohort size and local grain production is similar between the two types of households. However, for cohorts born close before and during the famine, the correlations diverge. As shown earlier, grain cultivation is negatively correlated with survival of agricultural populations born around the time of the famine, and it has no correlation with survival for non-agricultural populations of the same cohort. This reinforces the idea that 
procurement-which only affect agricultural populations-is a key factor for understanding the geographic patterns of the famine.

Note that while agricultural populations which produced more food experienced more famine, it is also the case that agricultural populations which were closer to cities also experienced more famine. This result is displayed in column (5) of Table 5. For this exercise, we used ArcGIS to calculate the geographic distance from the center of each county to the nearest urban center, where we considered 13 major urban centers (the thirteen largest in terms of population in 1959). ${ }^{33}$ Column (5) shows that for agricultural populations, being $1 \%$ further away from an urban center is correlated with $4.9 \%$ higher survival. The estimate is statistically significant at the $1 \%$ level. In Column (6), the estimate for non-agricultural populations show that distance from urban centers is uncorrelated with survival. The estimate is much smaller in magnitude as that of agricultural households, and it is statistically insignificant.

\section{Famine as a Consequence of Optimal Policy}

The conclusion from Section 4 is that the Great Famine must have had institutional causes but that the geographic patterns of famine intensity are not consistent with the patterns predicted by conventional institutional mechanisms. The empirical evidence from Section 4.2 does however provide some clues regarding the institutional mechanism which caused the famine. More specifically, it suggests that the mechanism behind the famine generated a positive correlation between food production and mortality among rural households experiencing procurement. Moreover, this mechanism involved non-agricultural households receiving food subsidies experiencing virtually no famine. Finally, our analysis using distances to major cities also suggests that the mechanism also involved rural regions closer to cities experiencing more famine.

In this section, we develop a model of constrained optimal policy which allows us to interpret the empirical evidence. This model implies that government policy-which is constrained by imperfect information and limited bureaucratic capacity-can amplify the rise in mortality resulting from a downturn in aggregate food production. Importantly, this model is consistent with this empirical evidence. We will use the model to explore a counterfactual exercise to contrast the implied food distribution under this policy to one under free markets.

\section{$5.1 \quad$ Intuitive Description}

Before presenting the model, we provide a simple stylized example to illustrate how under some public policies, a proportional cross-regional fall in production can lead to more severe famines in regions that historically produced more. Our model in the following section illustrates this formally and also identifies the relevant frictions motivating these public policies.

\footnotetext{
${ }^{33}$ These are also the major historic transportation network nodes identified in a study by Banerjee, Duflo and Qian (2009). See that paper for a detailed discussion.
} 
Two facts are key to this example. First, the fall in 1959 production was proportional to past local production, a fact which was illustrated in the previous section. Second, the central government set regional production targets proportional to past production. This rule makes intuitive sense as past production is a key predictor of current production for the central government, and the cost of procurement from high productivity regions is lower than for low productivity regions. We verify this claim using province level procurement and production data from the 1980s since, as discussed in Section 3, such data is unavailable for the 1950s. Nevertheless, given that the procurement system has not changed much since it was established in the early 1950s, the patterns we find using the 1980 data should in principle be indicative of the procurement patterns in the 1950s. ${ }^{34}$ Using the 1980s data, we find a strong positive correlation between past production and current targets. Figure 8 plots per capita targets against a four year moving average of past production. It shows a strong positive correlation.

To understand the impact of procurement targets which are correlated with past production, imagine two hypothetical collectives producing grain as shown in Table 5. Because these collectives are in a centrally planned economy, there is no interregional trade for grain. Collective A and Collective B have the same population and subsistence needs. However, Collective A can produce more grain due to better natural conditions. On average, in the years leading up to the famine, Collective A produced 130 tons of grain while Collective B produced 100 tons of grain. The central government wants to increase procurement over time since it knows that agricultural technology is improving. In 1959, the government sets procurement targets to be $10 \%$ more than previous production, at 143 tons and 110 tons for Collectives A and B, respectively. However, in 1959, there is an aggregate shock that causes production to decrease by $13 \%$ from previous years and collectives A and B produce 113 and 87 tons, respectively. Assume for simplicity that the subsistence need of each region is 100 tons of grain. Thus, in the presence of full redistribution of food, both regions would consume 100 tons of food and experience no famine. In the absence of such redistribution, two scenarios can emerge.

Scenario1: In the absence of any government redistribution program, Collective A will not have a famine because it has produced 13 tons of surplus grains. In contrast, Collective B which produced 13 tons less than what it needs will have a famine. Therefore, in this scenario, famine severity is negatively correlated with production, as is predicted by the conventional institutional view of famines.

Scenario2: Now imagine if a government redistribution program exists, and it takes the same form as that in China. The government is interested in procuring grain from the collectives for the urban regions, and it does so in a fashion which, in theory, leaves both collectives with the same retained grain. More specifically, should the two collectives meet their $10 \%$ growth rate target, they should both retain 100 tons

\footnotetext{
${ }^{34}$ Although collectives no longer existed officially in the 1980s, grain production targets- which now were the responsibility of village leaders to deliver-had not changed much since the 1950s. For this exercise we estimate a bivariate regression of the relationship between the natural logarithm of provinceyear level procurement targets and the natural logarithm of the average per capita surplus production over the past four years.
} 
of grain, so that 43 tons of grain are procured from Collective A and 10 tons of grain are procured from Collective B. However, there is in reality, a decrease of $13 \%$ in production so that the $10 \%$ growth target is not achieved. Local leaders may not be able to credibly convey this information to the central government which may perceive these reports as an effort to avoid procurement. ${ }^{35}$ Moreover, even if this information is credibly conveyed, the government may not be able to react sufficiently quickly. Consequently, procurement according to the $10 \%$ growth target occurs so that Collective A only retains 70 tons of grain, whereas Collective B retains 77 tons of grain so that it experiences a less severe famine. Therefore, in this scenario, famine severity is positively correlated with production, which is in line with our empirical evidence.

A key feature of the second scenario is that the central government cannot adjust its procurement target during the shortfall, and this occurs because the government cannot verify the presence of the shortfall in a timely fashion. In the case of China's famine, this most likely reflects the administrative and transportation costs of accumulating information. In practice, the government sent out tens of thousands of officials for procurement operations. Each official could only acquire information for a small set of locations and could not by himself verify the presence of an aggregate shock. Moreover, telecommunication was limited and time-consuming in late 1950s China. There were few telephone and telegraph lines between major cities, and almost none that linked rural areas. The railroads and roads had been devastated by the twelve year war with Japan (1933-45) and five year civil war between the Guomingtang (KMT) who ultimately retreated to Taiwan in 1949 (1945-49), and were just beginning to be repaired. Government officials often visited rural areas on bicycles and beasts of burden, and the transportation time between rural collectives and cities where the data was processed could easily have taken weeks at a time.

\subsection{Model}

In this section, we describe a theoretical environment in which a procurement formula analogous to that of the Chinese government is constrained optimal. Our model allows us to show how such a policy can amplify the rise in mortality resulting from a downturn in aggregate food production, and it allows us to show how such a policy generates patterns which are consistent with the empirical evidence.

Consider an economy with a continuum of size $M$ of rural regions labeled by $i \in[0, M]$ and a continuum of size $N$ of urban regions labeled by $i \in(M, M+N]$. Every region is populated by a mass $p_{i}$ of identical households and has a stochastic per-capita agricultural endowment $e_{i} \geq 0$ which follows the below stochastic process:

$$
\begin{aligned}
& e_{i}=\widehat{e}_{i} \eta \\
& \text { for } \eta=\left\{\begin{array}{ll}
1 & \text { with probability } \mu \\
\lambda & \text { with probability } 1-\mu
\end{array}\right. \text {, }
\end{aligned}
$$

\footnotetext{
${ }^{35}$ Alternatively, local leaders may be very reluctant to report the shortfall due to political pressure.
} 
where $\eta$ corresponds to an aggregate agricultural shock with $0<\lambda<1$ so that $1-$ $\lambda$ represents the lost agricultural production during an adverse agricultural shock. $\widehat{e}_{i}$ corresponds to the expected agricultural production of region $i$ during the high aggregate endowment shock. $\widehat{e}_{i}>0$ for rural regions and $\widehat{e}_{i}=0$ for urban regions since they do not produce any food, and therefore cannot observe the shock $\eta$. A given household in region $i$ 's budget constraint is

$$
c_{i}=e_{i}-\tau_{i}-\delta_{i} \tau_{i}^{2} / 2
$$

where $c_{i} \geq 0$ and $\tau_{i} \gtreqless 0$ represent household $i$ 's food consumption and taxes (procurement or subsidies), respectively. The parameter $\delta_{i} \geq 0$ captures transport costs to and from region $i$, where it is clear that transport costs are positive if $\delta_{i}>0$ and $\tau_{i}$ is not equal to zero. ${ }^{36}$ In our context this is particularly relevant since food is perishable. For example, $\delta_{i}$ would be very high if a region is very remote since it is more expensive to transfer food to and from this region. The government runs a balanced budget and does not engage in any public spending so that its budget constraint is

$$
\int_{0}^{M+N} p_{i} \tau_{i} d i=0
$$

The government is utilitarian over the urban population and utilitarian over the rural population, though it may weigh the urban population with a higher weight $\theta \geq 1$, which captures the fact that some members of the government can have a preference for satisfying the urban elite. Therefore, the government chooses a set of taxes and transfers to maximize the following object

$$
E\left\{\int_{0}^{M} p_{i} \pi\left(c_{i}\right) \chi d_{i}+\theta \int_{M}^{M+N} p_{i} \pi\left(c_{i}\right) \chi d i\right\}
$$

where $\pi(\cdot) \in[0,1]$ is a continuously differentiable, strictly increasing, and strictly concave function. $\pi(\cdot)$ corresponds to the probability of survival as a function of consumption, where $\chi$ corresponds to the value of life. ${ }^{37}$

It is clear in this environment that if $\delta_{i}=0$ for all households, the unconstrained optimum for the government is to treat every rural (urban) household equally so as to assign the same level of consumption to all rural (urban) households conditional on the agricultural shock. In such an environment, there would be no cross-regional variation in mortality risk in response to an agricultural shock with the exception that urban households may have a lower mortality risk than rural households if $\theta>1$.

Once the government takes into account that taxes and subsidies may involve waste because of transport costs, it will not implement this allocation. Importantly, in our

\footnotetext{
${ }^{36}$ All of our results hold if this cost is linear and the solution is interior.

${ }^{37}$ One can easily incorporate in our framework a motive for the government to save or deplete its current stock of grain by ignoring (7) and adding an additional term in the government objective's:

$$
V\left(\int_{0}^{M+N} p_{i}\left(e_{i}-c_{i}\right) d i\right)
$$

for $V(\cdot)$ which is increasing and concave. This refinement does not affect any of our results.
} 
environment, the government is subject to the following two key frictions. First, the government does not observe the realized agricultural production of region $i$. This is because households can hide part of their output in order to avoid being taxed by the government. Note however that the expected agricultural endowment under the high shock $\widehat{e}_{i}$ is known to the government. Second, the government has limited bureaucratic capacity: It can only condition region $i$ 's equilibrium tax on region $i$ 's report of its production. This is because it is too costly for the government to collect all of the reports from the regions and to condition taxes on the entire set of reports. ${ }^{38}$ This constraint is a realistic one to impose for China in the 1950s given the vast size of the country's territory relative to the level of development of its telecommunications infrastructure.

Together, these two frictions imply that the government cannot condition taxes on the realized agricultural shock. To see why, imagine if region $i$ 's tax depended on its reported income. Then region $i$ would always report the income associated with the lowest tax, so that under-reporting would take place and the region would always be subject to the same tax. Therefore, the only way for region $i$ to report its income is for the government to choose a level of taxation $\tau_{i}$ which is independent of region $i$ 's reported income. ${ }^{39}$

Consequently, the government's problem reduces to the optimal choice of a set $\tau=$ $\left\{\tau_{i}\right\}_{i \in[1, M+N]}$ which solves the following problem:

$$
\max _{\tau}(8) \text { s.t. (6) and (7). }
$$

Letting $\psi$ correspond to the Lagrange multiplier on constraint (7), the first order conditions to the government's program yield:

$$
\begin{aligned}
E\left\{\pi^{\prime}\left(c_{i}\right)\right\}\left(1+\delta_{i} \tau_{i}\right) & =\psi \forall i \in[0, M] \text { and } \\
\theta \pi^{\prime}\left(c_{i}\right)\left(1+\delta_{i} \tau_{i}\right) & =\psi \forall i \in(M, M+N] .
\end{aligned}
$$

Therefore, the government equates the expected marginal utility of agricultural consumption across the rural and urban households separately, adjusting for differences in transport cost. Note that this marginal utility is stochastic for the case of the rural regions but deterministic for the case of the urban regions since they are not subject to endowment shocks.

Equations (9) and (10) have some important implications which are summarized in the below proposition.

Proposition 1 (optimal policy) The optimal policy of the government has the following features

1. Given two rural regions $k$ and $l$ with $\widehat{e}_{k}>\widehat{e}_{l}$ and $\delta_{k}=\delta_{l}$, it follows that $\tau_{k}>\tau_{l}$ and that

$$
c_{k}>c_{l} \text { if } \eta=1 \text { and } c_{k}<c_{l} \text { if } \eta=\lambda .
$$

\footnotetext{
${ }^{38}$ Our underlying assumption is that a single leader from each region reports the region's income. In other words, all of the households in a given region can jointly coordinate in the under-reporting of income.

${ }^{39}$ As an aside, note that in a dynamic environment with persistent aggregate shocks, the government may be able to learn from region $i$ 's report ex-post in order to formulate its expectations of region's $i$ 's production in the following period.
} 
2. Given a rural region $k$ and an urban region $l$ with $\delta_{k}=\delta_{l}$, it follows that $c_{k}<c_{l}$ if $\eta=\lambda$.

3. Given two rural regions $k$ and $l$ with $\widehat{e}_{k}=\widehat{e}_{l} \geq \max \left\{c_{k}, c_{l}\right\}$ and, $\delta_{k}>\delta_{l}$, it follows that $\tau_{k}<\tau_{l}$ and that $c_{k}>c_{l}$.

Proof. (i) If $\widehat{e}_{k}>\widehat{e}_{l}$ and $\delta_{k}=\delta_{l}$, then $\tau_{k} \leq \tau_{l}$ would violate (9) given the concavity of $\pi(\cdot)$. (9) implies that either $c_{k}>c_{l}$ if $\eta=1$ and $c_{k}<c_{l}$ if $\eta=\lambda$ or that $c_{k}<c_{l}$ if $\eta=1$ and $c_{k}>c_{l}$ if $\eta=\lambda$. The second scenario is ruled out by (6). (ii) This follows by analogous logic taking into account that $\theta \geq 1$. (iii) This follows from (9) together with the concavity of $\pi(\cdot)$.

The first part of Proposition 1 states that for any two rural regions subject to the same transport costs, the more productive region experiences a higher tax burden, a higher food consumption during the aggregate food boom, and a lower food consumption during the aggregate food downturn. The second part of Proposition 1 states that this comparison applies to a rural region relative to an urban region since a rural region necessarily experiences lower food consumption during a downturn relative to an urban region. The third part of the proposition states that for any two rural regions with the same productivity and which experience a positive tax burden, the higher transport cost region experiences a lower tax burden and a higher food consumption.

The implication of the first part of Proposition 1 is that there is a negative relationship between mortality risk and food production in rural regions during an aggregate food downturn, which is consistent with the evidence which we document in Section 4 . This is because it is optimal for the government to tax the more productive region by more for redistributive purposes. Thus, because the tax cannot adjusted for proportional downfall in production, the more productive region suffers by more during the downturn. Note that an additional implication of Proposition 1 is that the more productive region should also experience lower mortality risk during an aggregate food boom via the exact same mechanism, which is also in line with the evidence in Section 4. The implication of the second part of Proposition 1 is that rural regions should experience a higher mortality risk relative to urban regions during an aggregate food downturn. This is because urban regions receive a constant food subsidy which does not fluctuate with the aggregate shock whereas the rural region's food consumption declines during the aggregate shock. ${ }^{40}$

As an illustration of the implications of the first two parts of the proposition, consider the constrained optimal allocation as the probability of a food downturn $\mu$ approaches 0 in an environment with zero transport costs. In this scenario, the optimal constrained policy sets consumption during the boom equal to $\bar{c}^{r}$ for rural regions and equal to $\bar{c}^{u}$ for urban regions, where the difference between $\bar{c}^{r}$ and $\bar{c}^{u}$ is rising in $\theta$, the government's preference for the urban population. Therefore, the positive correlation between food consumption and food production in the boom goes to zero as the probability of the downturn approaches zero. Note that in this scenario, the tax burden for a given rural region is equal to $\tau_{i}=\widehat{e}_{i}-\bar{c}^{r}$. This implies that the consumption of such a rural region

\footnotetext{
${ }^{40}$ Note that if $\theta=1$ is is the case that mortality risk in the rural region is lower relative to that of the urban region during the food boom, though this becomes less likely as $\theta$ rises.
} 
during the food downturn is equal to $\bar{c}^{r}-(1-\lambda) \widehat{e}_{i}$, so that there is a strong negative correlation between mortality risk and food production across these regions.

The implication of the third part of Proposition 1 is that in rural regions which are taxed, there is a positive relationship between transport costs from a given region and food consumption in this region. This is because it is inefficient for the government to extract food from regions from which this will involve high transport costs. Consequently, remote regions which are further away from cities experience a lower tax burden and hence experience a lower mortality risk during the aggregate food shortage, and this is also in line with the evidence in Section 4.

Proposition 2 (famine intensity) The value of $\int_{0}^{M+N} p_{i} \pi\left(c_{i}\right) d i$ is lower under optimal government policy relative to under the equal distribution of food.

Proof. $c_{i}=c_{j} \forall i \neq j$ for $\eta=1$ and $\eta=\lambda$ maximizes (8) for $\theta=1$ and therefore minimizes mortality risk given the concavity of $\pi(\cdot)$. Since optimal government policy cannot set $c_{i}=c_{j} \forall i \neq j \eta=1$ and $\eta=\lambda$ it cannot reach this maximum.

Proposition 2 implies that the intensity of famine is higher under optimal government policy than that which would be implied under the equal distribution of food. This is because the distribution of food under government policy is unequal so that some households receive very low food consumption and higher mortality risk. ${ }^{41}$

Note that this pattern is driven by three factors. First, if $\theta$ is very large, then the government is very biased towards urban households and is thus very likely to provide rural households with very low food consumption. Therefore, rural households suffer significantly more during the aggregate food shortage.

Second, if $\delta_{i}$ is very large, then food cannot be extracted from or delivered to some remote households, which implies that some households will not be able to consume as much food as others during the downturn, and this will lead to a higher mortality risk than under an equal distribution of food.

Most importantly, even in the absence of these two features-even if $\theta=1$ and $\delta_{i}=0$ $\forall i$-there is a higher mortality risk under the optimal policy relative to an equal distribution of food because of the most important factor driving the inefficiency in government policy: The government's information constraint and lack of bureaucratic capacity. The government cannot provide lower taxes to households during the food production bust since this would violate their incentives to truthfully report their production during the food production boom. More specifically, this constraint only applies to rural households but not to urban households which do not produce any food and therefore cannot underreport production. Moreover, this constraint applies more stringently to more productive relative to less productive regions since these have more to gain from under-reporting given the proportionality of the production shocks. Therefore, during an aggregate food downturn, rural regions experience a higher mortality risk relative to urban regions and

\footnotetext{
${ }^{41}$ Note that while we discuss our result in terms of aggregate mortality, one can easily discuss this result in terms of the fraction of the population below some arbitrarily chosen per-capita famine threshhold $c^{*}$. More specifically, one can choose $c^{*}<\int_{0}^{M+N} p_{i} \lambda \widehat{e}_{i}$ such that no household consumes less than $c^{*}$ under equal food distribution and some fraction of households consume less than $c^{*}$ under government policy.
} 
more productive rural regions experience a higher mortality risk relative to less productive urban regions.

Clearly, if the government could perfectly observe production, then it would equate the marginal mortality reduction from food across regions, after adjusting for $\delta_{i}$ differences and the fact that $\theta \geq 1$. Moreover, this would also be the case even if the government could not perfectly observe production but had enough bureaucratic capacity to condition taxes of one region on production reported in a neighboring region. In this circumstance, the government would be able to deduce one region's production from a truthful production report of a neighboring region (since production shocks are correlated). Moreover, a given region would thus never under-report its own production if it expects a neighboring region to also not under-report its production. Therefore, government policy would be able to adjust to the aggregate shock. Importantly, this would imply the absence of a negative correlation between food consumption and food production across rural regions during the aggregate downturn, so that the correlation which is consistent with the evidence would disappear.

\subsection{Counterfactual Exercise: Free Markets vs. Government}

A natural question given our interpretation of this historical episode is the extent to which the presence of free markets in China's economy would have been sufficient to avoid the tragic consequences of the downturn in aggregate food production. This question can be formulated in our model by introducing an additional second good which can be exchanged for food. We assume for this exercise that $\theta=1$ so that the government values rural household as much as urban households. This serves to focus our attention on distortions which are caused purely by trade costs and the informational capacity constraints on government policy.

To simplify exposition, imagine if every household $i$ has a constant exogenous endowment $y_{i}$ of this second good and that every household receives a linear utility from the consumption of this endowment which is denoted by $x_{i}$. This assumption of linearity appears like a reasonable first order approximation since it implies a much higher elasticity of demand for non-food relative to food consumption.

More specifically, following the realization of the aggregate shock, a given household $i$ solves the following problem:

$$
\begin{gathered}
\max _{c_{i}, x_{i}} \pi\left(c_{i}\right) \chi+x_{i} \\
\text { s.t. } \\
c_{i}+p x_{i}=e_{i}+p y_{i}-\delta_{i}\left(e_{i}-c_{i}\right)^{2} / 2,
\end{gathered}
$$

where $p$ represents the competitive equilibrium price of non-food in terms of food and the transport cost applies to the total amount of trade in food performed by household $i{ }^{42}$ First order conditions for the household yield:

$$
\pi^{\prime}\left(c_{i}\right) \chi=\delta_{i}\left(1+e_{i}-c_{i}\right) / p
$$

\footnotetext{
${ }^{42}$ Since the second consumption good is durable, we assume that its transport costs are negligible relative to food.
} 
so that the marginal benefit of food consumption is equal to its price adjusting for marginal trade costs. This first order condition implies that the price of food is higher during the food production downturn relative to the food production boom. Moreover, it implies that if $\delta_{i}=0$ so that trade costs are negligible, food consumption would equalized across regions, which implies that mortality risk is equalized across regions. This statement is generalized in the below proposition.

Proposition 3 The value of $\int_{0}^{M+N} \pi\left(c_{i}\right)$ di is higher under free markets relative to under optimal government policy.

Proof. (11) corresponds to the government's first order condition in the presence of perfect information which implies that the implied allocation strictly dominates that under imperfect information since the constraint set is relaxed.

This proposition states that there is lower aggregate mortality under free markets relative to constrained optimal policy. Clearly, the government would be able to replicate this free market outcome in the presence of better bureaucratic capacity since it would be able to learn the realization of the aggregate shock. However, institutional constraints on the government imply that the constrained optimal policy is dominated by the presence of free markets. The reason is that the free market price of food reflects the aggregate fundamentals of the economy, and this implies a more even allocation of food consumption across the economy and hence a lower degree of mortality risk.

As an aside, note that many of the patterns described in Proposition 1 would be overturned in the presence of free markets. In particular, if we control for transport costs or assume that they are non-negligible, then one would observe higher food consumption both during the boom and during the downturn in higher productivity regions under free markets. This is because these regions are richer and can therefore afford higher food consumption. This pattern would be at clear odds with the evidence from China's famine. This further implies that rural regions which produce a positive amount of food would also be consuming more food than urban regions experiencing the same trade costs which produce zero amounts of food. Note that the third prediction in Proposition 1 is preserved. It is still the case that for two rural regions with the same food production, the more remote region would consume a greater portion of food since the cost of selling it is too great. ${ }^{43}$

\subsection{Alternative Institutional Mechanisms}

We have provided a model which explains an institutional mechanism for the propagation of famine which is consistent with the data. A natural question is whether alternative institutional mechanisms could explain the geographic patterns behind China's famine.

\footnotetext{
${ }^{43}$ This example with two goods highlights an additional constraint on bureaucratic capacity since it is clear that in the presence of multiple goods, incentives for truthful reporting of income can be provided by altering the intratemporal margin across households. Our analysis thus implicitly assumes that this is impossible since we are effectively considering a setting in which the redistribution of food occurs independently of the redistribution of non-food.
} 
In considering such an alternative explanation, the following fact is clear from our model: the malevolence or self-interest of politicians alone would not generally cause the geographic patterns observed. More specifically, one could interpret the self-interest of politicians as manifesting itself in favoritism of some regions over others so that some regions would receive more weight in the social welfare function. In the presence of perfect information, this would predict that some regions would consistently experience higher mortality both during an food production boom and during a downturn. Given that food productivity is persistent and that more productive regions produce more both during the downturn as well as during the boom, this would imply that politicians systematically favor less productive regions by more so that these would experience less mortality during the famine. However, this would also imply that less productive regions should experience less mortality during the food production boom, an implication which is refuted by our analysis in Section 4 which shows that these regions experienced higher mortality than the more productive regions in the years prior to the famine. Therefore, while the self-interest of politicians may have played some role-particularly if this manifested itself in favoritism towards cities relative to rural regions-on its own it cannot explain the patterns generated by China's famine.

An additional issue to consider is the fact that rather than local bureaucrats being tempted to under-report production-as they are in the model-it is possible that they were actually more tempted to over-report production for various reasons related to career concerns and reputation. This possibility leaves several important issues to consider. First, within the context of our model, this would again imply that the government would be unable to trust the information relayed by the region leader, so that the government would set taxes independently of the message received from the region leader. Thus, though the precise interpretation of the nature of the informational friction would be modified, none of our results would change since the optimal constrained policy would be identical to the one we derive given the limited information processing ability of the government. A second issue to consider lies outside of the context of our model since the propensity to over-report production may differ systematically among region leaders and this variation may be related to other features of cross-regional institutional variation. More specifically, famine for a given region may have been caused by a regional institutional failure which is also responsible for causing over-reporting, and this mechanism would generate a positive relationship between mortality and reported food production. Nevertheless, this mechanism alone would not generate a positive relationship between our agricultural suitability measure-which is not contaminated by reporting biases-and famine intensity of the sort that we find in the data.

An additional issue to discuss which is clear from our model and which is related to the conventional institutional mechanism for famine is that the transport costs experienced by the government alone could not have generated the famine. In fact, these costs should have been sufficiently low that the government was able to deliver sufficient food to urban regions which produced virtually no food. More specifically, in the context of our model, under perfect information and trade costs, it would still be the case that controlling for trade costs, high productivity regions should experience fewer, as opposed to more, famine deaths, a fact which is refuted by the evidence. 
A final issue to consider is the potential incompetence of the government. In the context of the model, this could manifest itself in the government's ex-ante miscalculation of key parameters in the environment such as the expected regional production $\widehat{e}_{i}$, the size of the downturn $1-\lambda$, and the probability of the downturn $1-\mu$. Note that absent any imperfect information or limited bureaucratic capacity, these miscalculations would have no impact on the allocation since the government would have perfect knowledge of the realization of the shock ex-post. Nevertheless, one issue to keep in mind, is that these types of systematic biases by the government could serve to reinforce our conclusions once we consider how these interact with the constraints of imperfect information or limited bureaucratic capacity. For example, if the government underestimates the magnitude of the downturn $1-\lambda$ or alternatively underestimates its probability $1-\mu$, then one can show that this raises the extent of the famine and reinforces the positive correlation between food production and mortality during the downturn. Moreover, if the government overestimates expected production $\widehat{e}_{i}$ by more for high productivity regions relative to low productivity regions, then this would also imply a heavier tax burden on high productivity regions and reinforce our conclusions. In sum, the main insight from our model is that even in the absence of additional factors such as government incompetence or self-interested politicians, the constraints of imperfect information and limited bureaucratic capacity are enough to cause a well intentioned government to generate a famine which fits the patterns in the data.

\section{Conclusion}

This paper provides a rigorous analysis of the institutional causes of China's Great Famine. We add two facts to the general understanding of China's Famine: the production fall in 1959 by itself could not have caused a famine and it could not have caused a famine that was more intense in regions that produced more grain. Moreover, we contribute to studies of causes of the causes of famine more generally by presenting a concrete example of an institutionally driven famine. We show that the mechanism for famine can be very different in a centrally planned economy relative to a market economy since it produces very different patterns of devastation.

Our analysis leaves open several interesting directions for future research. First, a natural future direction is to study whether a similar institutional mechanism was responsible in other famines in centrally planned economies, in particular for the Ukrainian Famine (1932-33). Second, it is important to study whether the geographic patterns predicted by the institutional mechanism of Sen (1981)-which were not present in China-are present in market economies which experienced famine. Finally, our model of Section 5 leaves open several interesting theoretical questions. Our counterfactual exercise implicitly assumed that market prices could serve to aggregate information on food production whereas the limited institutional capacity of the government prevented it from doing so. While this argument is in line with historical arguments made by economists such as Von Mises (1921) and Hayek (1944), the exact theoretical reason as to why markets are more efficient than governments at aggregating information is an important question for future theoretical research. 


\section{References}

[1] Acemoglu, D., S. Johnson, and J. A. Robinson. "The Colonial Origins of Comparative Development: An Empirical Investigation." American Economic Review 91 (2001): 1369-1401.

[2] Albanesi, Stefania and Christopher Sleet. "Dynamic Optimal Taxation with Private Information." Review of Economic Studies 73 (2006) 1-30.

[3] Ashton, Basil, Kenneth Hill, Alan Piazza, and Robin Zeitz. "Famine in China, 19581961." Population and Development Review 10 (1984): 613-45.

[4] Banister, Judith. China's Changing Population. Stanford, CA: Stanford University Press, 1987.

[5] Becker, Jasper. Hungry Ghosts: China's Secret Famine. London: John Murray Publishers, 1996.

[6] Besley, Timothy. "Property Rights and Investment Incentives: Theory and Evidence from Ghana." Journal of Political Economy 103.5 (1995): 903-37.

[7] Besley, Timothy, and Torsten Persson. "The Origins of State Capacity: Property Rights, Taxation, and Politics." NBER Working Papers 13028 (2007).

[8] Blayo, Y. "Political events and birth rates in China since 1950." Population 46.6 (1991): 1589-615.

[9] Bloom, David E. and Jeffrey D. Sachs. "Geography, Demography, and Economic Growth in Africa." Brookings Papers on Economic Activity 2 (1998): 207-73.

[10] Burgess, Robin and Donaldson, David (2009) "Can Trade Openness Reduce Real Income Volatility? Evidence from Colonial India's Era of Famine" MIT Working Paper.

[11] Chang, Gene Hsin, and Guanzhong James Wen. "Communal Dining and the Chinese Famine of 1958-1961." Economic Development and Cultural Change 46 (1997): 1-34.

[12] Chen, Y. and L-A. Zhou. "The long term health and economic consequences of 19591961 famine in China." Journal of Health Economics 26 (2007): 659-681.

[13] Cohen, Charles and Eric D. Werker. "The Political Economy of Natural Disasters." Journal of Conflict Resolution 52.6 (2008): 795-819.

[14] Dreze, Jean. The Economics of Famine. Elgar Reference Collection, International Library of Critical Writings in Economics, Cheltenham, U.K. and Northampton, Mass, vol. 101, 1999.

[15] Pei-kai, Cheng et al. The Search for Modern China: A Documentary Collection. New York: Newton, 1999. 
[16] Easterly, W., and R. Levine. "Tropics, Germs, and Crops: How Endowments Influence Economic Development." Journal of Monetary Economics 50 (2003): 3-40.

[17] Ellman, Michael. "The 1947 Soviet Famine and the Entitlement Approach to Famines." Cambridge Journal of Economics 24.5 (2000): 603-30.

[18] Fairbank, John King. The Great Chinese Revolution, 1800-1985: 1800-1985. New York: Harper \& Row, 1986.

[19] Gallup, J. L., J. D. Sachs, and A. D. Mellinger. "Geography and Economic Development." National Bureau of Economic Research Working Paper No. w6849 (1998).

[20] Giles, John, Albert Park and Juwei Zhang. "The Great Proletarian Cultural Revolution, Disruptions to Education, and Returns to Schooling in Urban China" Michigan State University (2006).

[21] Golosov, Mikhail, Narayana Kocherlakota, and Aleh Tsyvinski. "Optimal Indirect and Capital Taxation." Review of Economic Studies 70 (2003): 569-587.

[22] Hall, Robert E. and Jones, Charles I. "Why Do Some Countries Produce So Much More Output Per Worker Than Others?" Quarterly Journal of Economics 114.1 (1999): 83-116.

[23] Hayek, F.A. and Friedman Milton. The Road to Freedom. 50th Anniversary Edition, University Of Chicago Press, 1994.

[24] Hickson, Charles R. and Turner, John D. "Pre- and Post-famine Indices of Irish Equity Prices." European Review of Economic History 12.1 (2008): 3-38.

[25] Johnson, D. Gale. "China's Great Famine: Introductory Remarks." China Economic Review 9 (1998): 103-9.

[26] Kahn, Matthew. "The Death Toll from Natural Disasters: The Role of Income, Geography, and Institutions." Review of Economics and Statistics 87.2 (2005): 271-284.

[27] Kueh, Y. Agricultural Instability in China, 1931-1990: Weather, Technology and Institutions. Oxford: Clarendon, 1995.

[28] Wei, Li and Dennis Yang. "The Great Leap Forward: Anatomy of a Central Planning Disaster." Journal of Political Economy 113.4 (2005): 840-77.

[29] Lavely, William R. "Age Pattern of Chinese Marital Fertility 1950-1980." Demography 23.3 (1986):419-434.

[30] Lin, Justin Yifu. "Collectivization and China's Agricultural Crisis in 1959-1961." Journal of Political Economy 98 (1990): 1228-52.

[31] Justin Yifu Lin and Dennis Tao Yang. "Food Availability, Entitlements and the Chinese Famine of 1959-61" The Economic Journal 110.460 (2000): 136-158. 
[32] McGregor, Patrick. "Demographic Pressure and the Irish Famine: Malthus after Mokyr." Land Economics 65.3 (1989): 228-38.

[33] Meng, Xin and Qian, Nancy. 'The Long Run Consequences of Famine on Survivors: Evidence from China's Great Famine 1959-61." NBER Working Paper (2009).

[34] Mirrlees, James. "An Exploration in the Theory of Optimum Income Taxation." Review of Economic Studies 38 (1971): 175-208.

[35] Mises, Ludwig Von. Economic Calculation in the Socialist Commonwealth. The Ludwig Von Mises Institute 1990 Edition, 1920.

[36] North, Douglass C. Structure and Change in Economic History. New York: W.W. Norton \& Co., 1981.

[37] Nunn, Nathan and Nancy Qian. "The Historical Impact of the Potato on World Population." Brown University Working Paper (2008).

[38] O'Boyle, Edward J. "Classical Economics and the Great Irish Famine: A Study in Limits." Forum for Social Economics 35.2 (2006): 21-53.

[39] O'Grada, Cormac, et al. Ireland's Great Famine: Interdisciplinary Perspectives. Dublin: University College Dublin Press, 2006.

[40] Oi, Jean. State and Peasant in Contemporary China: The Political Economy of Village Government. Berkeley: University of California Press, XXI, 1989.

[41] O'Rourke, John. The History of the Great Irish Famine of 1847: With Notices of Earlier Irish Famines. Dublin: BiblioBazaar, LLC, 2007.

[42] Procyk, Oksana. Famine in the Soviet Ukraine, 1932-1933: A Memorial Exhibition. Cambridge: Harvard College Library, 1986.

[43] Perkins, Dwight H., and Shahid Yusuf. Rural Development in China. Baltimore: Johns Hopkins University Press (for The World Bank), 1984.

[44] Torsten, Persson, Gerard Roland and Guido Tabellini. "How Do Electoral Rules Shape Party Structures, Government Coalitions, and Economic Policies?" NBER Working Papers 10176 (2003) .

[45] Torsten Persson, Guido Tabellini and Trebbi, Francesco. "Electoral Rules and Corruption." CEPR Discussion Papers 2741 (2001).

[46] Torsten, Persson and Guido Tabellini. "Constitutions and Economic Policy." Journal of Economic Perspectives, American Economic Association 18.1 (2004): 75-98.

[47] Ravallion, Martin. "Famines and Economics." Journal of Economic Literature 35 (1997): 1205-42. 
[48] Rodrik, Dani, Arvind Subramanian, and Francesco Trebbi. "Institutions Rule: The Primacy of Institutions over Geography and Integration in Economic Development." Journal of Economic Growth (2007).

[49] Sachs, J. "Institutions Don't Rule: Direct Effects of Geography on Per Capita Income," National Bureau of Economic Research Working Paper No. 9490 (2003).

[50] Sen, Amartya. Poverty and Famines: An Essay on Entitlement and Deprivation. Oxford: Clarendon, 1981.

[51] Twitchett, Denis and Fairbank, John K. Cambridge History of China, 14 (1985): 378386.

[52] Unger, Jon. Education Under Mao. New York: Columbia University Press. 82.3. 1982: 393-408.

[53] Vallin, Jacques. "A New Estimate of Ukrainian Population Losses during the Crises of the 1930s and 1940s." Population Studies 56.3 (2002): 249-64.

[54] Walker, Kenneth R. Food Grain Procurement and Consumption in China. Cambridge: Cambridge University Press, 1984.

[55] Webb, Patrick and Von Braun, Joachim Famine and Food Security in Ethiopia: Lessons for Africa. New York: John Wiley, (1994).

[56] West, Lorraine and Zhao, Yaohui. Rural-urban migration in China: the past and present. Institute for East Asian Studies, University of California, Berkeley, 2000.

[57] Wen, Guanzhong James. "Total Factor Productivity Change in China's Farming Sector: 1952-1989." Economic Development and Cultural Change 42 (1993): 1-41.

[58] Yang, Dali L. Calamity and Reform in China: State, Rural Society, and Institutional Change since the Great Leap Famine. Stanford, CA: Stanford University Press, 1996.

[59] Yang, Dennis. "China's Agricultural Crisis and Famine of 1959-61: A Survey and Comparison to Soviet Famines." Comparative Economic Studies 50 (2008): 1-20. Yao, Shujie. "A Note on the Causal Factors of China's Famine in 1959-1961." Journal of Political Economy 107.6 (1999): 1365-69.

[60] Zeckhauser, Richard. "The Economics of Catastrophes." Journal of Risk and Uncertainty 12 (1996): 113-140. 
Table 1: Historical Grain Production, Procurement, and Retention from Li and Yang (2005)

\begin{tabular}{|c|c|c|c|c|c|c|c|}
\hline \multirow[b]{4}{*}{ Year } & \multicolumn{7}{|c|}{ Li and Yang (2005) 21 Provinces Published by Ministry of Agriculture in 1989} \\
\hline & \multirow[b]{2}{*}{$\begin{array}{c}\text { (Millions } \\
\text { Tons) }\end{array}$} & \multirow{2}{*}{$\begin{array}{c}\text { Grain Prod } \\
\text { Growth } \\
\text { Rate } \\
\end{array}$} & \multirow[b]{2}{*}{$\begin{array}{c}\text { Growth } \\
\text { Rate 4MA }\end{array}$} & \multicolumn{2}{|c|}{ Retained Grain } & \multicolumn{2}{|c|}{ Grain Procurement } \\
\hline & & & & (kg/Person) & $\%$ of Prod* & $\begin{array}{l}\text { (Millions } \\
\text { Tons) }\end{array}$ & $\begin{array}{c}\% \text { of } \\
\text { "Surplus" } \\
\text { Production ** }\end{array}$ \\
\hline & $(1)$ & $(2)$ & $(3)$ & $(4)$ & $(5)$ & $(6)$ & $(7)$ \\
\hline 1952 & 164 & & & 260 & 0.80 & 33 & 0.85 \\
\hline 1953 & 167 & 0.02 & & 242 & 0.72 & 47 & 1.12 \\
\hline 1954 & 170 & 0.02 & & 228 & 0.70 & 51 & 1.14 \\
\hline 1955 & 184 & 0.08 & & 256 & 0.74 & 48 & 0.82 \\
\hline 1956 & 193 & 0.05 & 0.04 & 284 & 0.79 & 40 & 0.59 \\
\hline 1957 & 195 & 0.01 & 0.04 & 273 & 0.76 & 46 & 0.66 \\
\hline 1958 & 200 & 0.03 & 0.04 & 268 & 0.74 & 52 & 0.69 \\
\hline 1959 & 170 & -0.15 & -0.02 & 193 & 0.62 & 64 & 1.43 \\
\hline 1960 & 143 & -0.16 & -0.07 & 182 & 0.67 & 47 & 2.64 \\
\hline 1961 & 148 & 0.03 & -0.06 & 209 & 0.75 & 37 & 1.62 \\
\hline 1962 & 160 & 0.08 & -0.05 & 229 & 0.80 & 32 & 0.92 \\
\hline 1963 & 170 & 0.06 & 0.00 & 231 & 0.78 & 37 & 0.83 \\
\hline 1964 & 188 & 0.11 & 0.07 & 256 & 0.79 & 40 & 0.64 \\
\hline 1965 & 195 & 0.04 & 0.07 & 261 & 0.80 & 39 & 0.56 \\
\hline 1966 & 214 & 0.10 & 0.08 & 282 & 0.81 & 41 & 0.46 \\
\hline 1967 & 218 & 0.02 & 0.06 & 281 & 0.81 & 41 & 0.44 \\
\hline 1968 & 209 & -0.04 & 0.03 & 261 & 0.81 & 40 & 0.48 \\
\hline 1969 & 211 & 0.01 & 0.02 & 259 & 0.82 & 38 & 0.44 \\
\hline 1970 & 240 & 0.14 & 0.03 & 282 & 0.81 & 46 & 0.40 \\
\hline 1971 & 250 & 0.04 & 0.04 & 293 & 0.82 & 44 & 0.35 \\
\hline 1972 & 241 & -0.04 & 0.04 & 298 & 0.84 & 39 & 0.34 \\
\hline 1973 & 265 & 0.10 & 0.06 & 293 & 0.82 & 48 & 0.34 \\
\hline 1974 & 275 & 0.04 & 0.04 & 303 & 0.83 & 47 & 0.31 \\
\hline 1975 & 285 & 0.04 & 0.03 & 304 & 0.81 & 53 & 0.33 \\
\hline 1976 & 286 & 0.00 & 0.04 & 306 & 0.83 & 49 & 0.30 \\
\hline
\end{tabular}

*Column (5) = [Column (1) - Column (6)]/Column (1).

** We assume aggregate subsistence levels to be 125.2 million tons. $(7)=(6) /[(1)-125.2]$

Source: Columns (1), (4), and (6) are taken from Li and Yang (2005) (Original Sources: Ministry of Agriculture (1989)). 
Table 2: Historical Grain Production, Population and Subsistence Needs

\begin{tabular}{|c|c|c|c|c|c|c|c|c|c|c|c|}
\hline \multirow[b]{4}{*}{ Year } & \multicolumn{11}{|c|}{30 Provinces Published by NBS in 1999} \\
\hline & \multirow[b]{2}{*}{$\begin{array}{c}\text { Grain Prod } \\
\text { (Millions } \\
\text { Tons) }\end{array}$} & \multirow[b]{2}{*}{$\begin{array}{c}\text { Population } \\
\text { (10000) }\end{array}$} & \multicolumn{2}{|c|}{$\begin{array}{c}228 \text { kg/person, 2,240 } \\
\text { Calories }\end{array}$} & \multicolumn{2}{|c|}{$92 \mathrm{Kg} /$ person, 900 Calories } & \multirow{3}{*}{$\begin{array}{c}\text { Province } \\
\\
(7)\end{array}$} & \multirow{3}{*}{$\begin{array}{c}1959 / 60 \\
\text { Death Rate } \\
\\
(8) \\
\end{array}$} & \multirow{3}{*}{$\begin{array}{c}1959 \text { Grain } \\
\text { Prod } \\
\\
\text { Kg/Person } \\
(9) \\
\end{array}$} & \multicolumn{2}{|c|}{1959 "Surplus" } \\
\hline & & & $\begin{array}{c}\text { Needed } \\
\text { (Million } \\
\text { Tons) }\end{array}$ & $\begin{array}{c}\text { Grain } \\
\text { Surplus } \\
\text { (Million } \\
\text { Tons) }\end{array}$ & $\begin{array}{c}\text { Needed } \\
\text { (Million } \\
\text { Tons) }\end{array}$ & $\begin{array}{c}\text { Grain } \\
\text { Surplus } \\
\text { (Million } \\
\text { Tons) }\end{array}$ & & & & $\begin{array}{c}2,240 \\
\text { Calories }\end{array}$ & $\begin{array}{c}900 \\
\text { Calories }\end{array}$ \\
\hline & $(1)$ & $(2)$ & (3) & $(4)$ & $(5)$ & $(6)$ & & & & $(10)$ & $(11)$ \\
\hline 1949 & 101.59 & 54167 & 124 & -22 & 50 & 52 & Shanghai & 6.9 & 107.02 & -120.98 & 16.02 \\
\hline 1950 & 119.88 & 55196 & 126 & -6 & 51 & 69 & Beijing & 9.14 & 82.01 & -145.99 & -8.99 \\
\hline 1951 & 128.12 & 56300 & 128 & 0 & 52 & 77 & Neimeng & 9.4 & 412.16 & 184.16 & 321.16 \\
\hline 1952 & 157.42 & 57482 & 131 & 26 & 53 & 105 & Jilin & 10.13 & 401.07 & 173.07 & 310.07 \\
\hline 1953 & 148.56 & 58796 & 134 & 15 & 54 & 95 & Tianjin & 10.34 & 91.42 & -136.58 & 0.42 \\
\hline 1954 & 149.44 & 60266 & 137 & 12 & 55 & 94 & Heilongjiang & 10.52 & 505.95 & 277.95 & 414.95 \\
\hline 1955 & 163.97 & 61456 & 140 & 24 & 56 & 108 & Shanxi & 11.21 & 244.48 & 16.48 & 153.48 \\
\hline 1956 & 165.84 & 62828 & 143 & 23 & 58 & 108 & Liaoning & 11.5 & 235.91 & 7.91 & 144.91 \\
\hline 1957 & 174.37 & 64563 & 147 & 27 & 59 & 115 & Zhejiang & 11.88 & 382.06 & 154.06 & 291.06 \\
\hline 1958 & 169.82 & 65994 & 150 & 19 & 60 & 109 & Shan'xi & 12.27 & 251.99 & 23.99 & 160.99 \\
\hline 1959 & 148.33 & 67207 & 153 & -5 & 62 & 87 & Ningxia & 13.9 & 303.70 & 75.70 & 212.70 \\
\hline 1960 & 127.66 & 66207 & 151 & -23 & 61 & 67 & Guangdong & 15.24 & 242.70 & 14.70 & 151.70 \\
\hline 1961 & 122.98 & 65859 & 150 & -27 & 60 & 63 & Xinjiang & 15.67 & 304.35 & 76.35 & 213.35 \\
\hline 1962 & 148.19 & 67295 & 153 & -5 & 62 & 87 & Hebei & 15.8 & 195.12 & -32.88 & 104.12 \\
\hline 1963 & 146.59 & 69172 & 158 & -11 & 63 & 83 & Jiangxi & 16.06 & 314.36 & 86.36 & 223.36 \\
\hline 1964 & 166.12 & 70499 & 161 & 5 & 65 & 102 & Jiangshu & 18.41 & 231.42 & 3.42 & 140.42 \\
\hline 1965 & 201.67 & 72538 & 165 & 36 & 66 & 135 & Fujian & 20.7 & 259.23 & 31.23 & 168.23 \\
\hline 1966 & 197.29 & 74542 & 170 & 27 & 68 & 129 & Hubei & 21.21 & 241.07 & 13.07 & 150.07 \\
\hline 1967 & 201.23 & 76368 & 174 & 27 & 70 & 131 & Shandong & 23.6 & 195.24 & -32.76 & 104.24 \\
\hline 1968 & 193.80 & 78534 & 179 & 15 & 72 & 122 & Yunnan & 26.26 & 265.26 & 37.26 & 174.26 \\
\hline 1969 & 193.76 & 80671 & 184 & 10 & 74 & 120 & Hunan & 29.42 & 300.32 & 72.32 & 209.32 \\
\hline 1970 & 241.66 & 82992 & 189 & 52 & 76 & 166 & Guangxi & 29.46 & 246.98 & 18.98 & 155.98 \\
\hline 1971 & 238.21 & 85229 & 194 & 44 & 78 & 160 & Henan & 39.56 & 195.72 & -32.28 & 104.72 \\
\hline 1972 & 229.14 & 87177 & 199 & 30 & 80 & 149 & Qinghai & 40.73 & 200.49 & -27.51 & 109.49 \\
\hline 1973 & 254.98 & 89211 & 203 & 52 & 82 & 173 & Gansu & 41.32 & 223.95 & -4.05 & 132.95 \\
\hline 1974 & 264.20 & 90859 & 207 & 57 & 83 & 181 & Guizhou & 52.33 & 242.67 & 14.67 & 151.67 \\
\hline 1975 & 296.58 & 92420 & 211 & 86 & 85 & 212 & Anhui & 68.58 & 204.55 & -23.45 & 113.55 \\
\hline \multirow[t]{2}{*}{1976} & 276.65 & 93717 & 214 & 63 & 86 & 191 & Hainan & $\mathrm{N} / \mathrm{A}$ & 181.51 & -46.49 & 90.51 \\
\hline & & & & & & & Sichuan & $\mathrm{N} / \mathrm{A}$ & N/A & N/A & $\mathrm{N} / \mathrm{A}$ \\
\hline
\end{tabular}

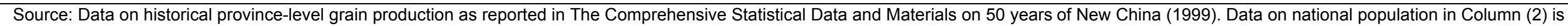
reported by The China Population Institute and Research Center.

Note: Total production reported in column (1) is aggregate from province level production. This excludes Sichuan, a major grain producer, for which data is not available. 
Table 3: Descriptive Statistics

\begin{tabular}{|c|c|c|c|c|c|c|}
\hline & Obs & Mean & Std. Err. & & & \\
\hline & \multicolumn{3}{|c|}{ A. Province Level } & & & \\
\hline Population (10,000 People) & 503 & 2034.34 & 62.98 & & & \\
\hline Death Rate (per 1,000 People) & 452 & 12.42 & 0.26 & & & \\
\hline Death Rate in $1959 / 60$ (per 1,000 People) & 486 & 21.91 & 0.67 & & & \\
\hline Annual Grain Production (Kg) & 504 & 542826.60 & 16546.57 & & & \\
\hline Annual Grain Production 1954-58 (Kg) & 522 & 550292.60 & 16265.50 & & & \\
\hline Grain Production in 1959 & 504 & 529101.80 & 14807.91 & & & \\
\hline Annual Per Capital Grain Production & 500 & 279.74 & 8.02 & & & \\
\hline \multirow[t]{4}{*}{ Annual Per Capital Grain Production in 1959} & 504 & 252.24 & 4.11 & & & \\
\hline & \multicolumn{6}{|c|}{ B. County Level } \\
\hline & \multicolumn{3}{|c|}{ Agricultural Households } & \multicolumn{3}{|c|}{ Non-Agricultural Households } \\
\hline & Obs & Mean & Std. Err. & Obs & Mean & Std. Err \\
\hline Average Cohort Size (1942-66) & 46212 & 37.14 & 0.18 & 35175 & 21.62 & 0.18 \\
\hline Average Famine Cohort Size (1959-61) & 45736 & 33.01 & 0.14 & 32381 & 24.75 & 0.19 \\
\hline Average Pre-Famine Cohort Size (1954-57) & 46004 & 49.68 & 0.21 & 33937 & 29.59 & 0.23 \\
\hline $\begin{array}{l}\text { Ratio of Famine/Pre-Famine Cohort Size } \\
\text { Fraction of Counties where Ratio of Famine/Pre-Famine }\end{array}$ & 45640 & 0.72 & 0.00 & 31934 & 0.85 & 0.00 \\
\hline Cohort Size $<1$ & 46212 & 0.85 & 0.00 & 35175 & 0.65 & 0.00 \\
\hline Fraction of Land Suitable for Rice or Wheat & 46212 & 0.14 & 0.00 & 35175 & 0.15 & 0.00 \\
\hline
\end{tabular}

Cohort sizes are $1 \%$ of actual cohort sizes.

Each observation is a birth year $\mathrm{x}$ birth county cell. 
Table 4: The Correlation between Grain Production and Famine Severity at the Province Level

\begin{tabular}{|c|c|c|c|c|c|c|c|c|c|c|c|c|}
\hline & \multicolumn{12}{|c|}{ Dependent Variables } \\
\hline & \multicolumn{2}{|c|}{ LnTotalPop } & \multicolumn{2}{|c|}{ LnDeaths } & \multicolumn{2}{|c|}{ LnTotalPop } & \multicolumn{2}{|c|}{ LnDeaths } & \multicolumn{2}{|c|}{ LnTotalPop } & \multicolumn{2}{|c|}{ LnDeaths } \\
\hline & $\begin{array}{c}\text { Non- } \\
\text { Famine } \\
(1)\end{array}$ & $\begin{array}{c}\text { Famine } \\
(2)\end{array}$ & $\begin{array}{c}\text { Non- } \\
\text { Famine } \\
(3)\end{array}$ & $\begin{array}{c}\text { Famine } \\
(4)\end{array}$ & $\begin{array}{l}\text { All } \\
(5)\end{array}$ & $\begin{array}{l}\text { All } \\
(6)\end{array}$ & $\begin{array}{l}\text { All } \\
(7)\end{array}$ & $\begin{array}{l}\text { All } \\
(8) \\
\end{array}$ & $\begin{array}{l}\text { All } \\
(9)\end{array}$ & $\begin{array}{c}\text { All } \\
(10)\end{array}$ & $\begin{array}{c}\text { All } \\
(11)\end{array}$ & $\begin{array}{c}\text { All } \\
(12)\end{array}$ \\
\hline Ln Grain Prod & $\begin{array}{c}0.256 \\
(0.172)\end{array}$ & $\begin{array}{l}0.00375 \\
(0.0859)\end{array}$ & $\begin{array}{l}-0.261 \\
(0.165)\end{array}$ & $\begin{array}{c}0.373 \\
(0.445)\end{array}$ & & & & & & & & \\
\hline Ln Grain Prod 1959 x 1960 Dummy & & & & & $\begin{array}{c}-0.0804 \\
(0.0337)\end{array}$ & $\begin{array}{l}-0.0685 \\
(0.0257)\end{array}$ & $\begin{array}{l}0.0797 \\
(0.104)\end{array}$ & $\begin{array}{l}0.0702 \\
(0.101)\end{array}$ & & & & \\
\hline Ln Grain Prod 1954-58 x 1960 Dummy & & & & & & & & & $\begin{array}{l}-0.0800 \\
(0.0305)\end{array}$ & $\begin{array}{l}-0.0659 \\
(0.0242)\end{array}$ & $\begin{array}{l}0.0995 \\
(0.106)\end{array}$ & $\begin{array}{l}0.0817 \\
(0.103)\end{array}$ \\
\hline Controls & & & & & & & & & & & & \\
\hline Province $\mathrm{x}$ Year Time Trends & $\mathrm{N}$ & $\mathrm{N}$ & $\mathrm{N}$ & $\mathrm{N}$ & $\mathrm{N}$ & $\mathrm{Y}$ & $\mathrm{N}$ & $\mathrm{Y}$ & $\mathrm{N}$ & $\mathrm{Y}$ & $\mathrm{N}$ & Y \\
\hline $\begin{array}{l}\text { Government Spending on Agriculture } \\
\text { Government Spending on Health, Edu \& }\end{array}$ & $\mathrm{N}$ & $\mathrm{N}$ & $\mathrm{N}$ & $\mathrm{N}$ & $\mathrm{N}$ & $\mathrm{Y}$ & $\mathrm{N}$ & Y & $\mathrm{N}$ & $\mathrm{Y}$ & $\mathrm{N}$ & Y \\
\hline $\begin{array}{l}\text { Science } \\
\text { Number of Teachers in Primary and }\end{array}$ & $\mathrm{N}$ & $\mathrm{N}$ & $\mathrm{N}$ & $\mathrm{N}$ & $\mathrm{N}$ & $\mathrm{Y}$ & $\mathrm{N}$ & $\mathrm{Y}$ & $\mathrm{N}$ & $\mathrm{Y}$ & $\mathrm{N}$ & $\mathrm{Y}$ \\
\hline Secondary & $\mathrm{N}$ & $\mathrm{N}$ & $\mathrm{N}$ & $\mathrm{N}$ & $\mathrm{N}$ & $\mathrm{Y}$ & $\mathrm{N}$ & $\mathrm{Y}$ & $\mathrm{N}$ & $\mathrm{Y}$ & $\mathrm{N}$ & $\mathrm{Y}$ \\
\hline Observations & 416 & 84 & 369 & 81 & 499 & 357 & 448 & 333 & 503 & 357 & 452 & 333 \\
\hline R-squared & 0.970 & 0.999 & 0.564 & 0.661 & 0.969 & 0.974 & 0.558 & 0.764 & 0.970 & 0.974 & 0.561 & 0.765 \\
\hline
\end{tabular}


Table 5: The Correlation between Grain Suitability and Famine Severity at the County Level

\begin{tabular}{|c|c|c|c|c|c|c|}
\hline & \multicolumn{6}{|c|}{ Dependent Variables: Ln Cohort Size } \\
\hline & \multicolumn{2}{|c|}{ Agricultural } & \multicolumn{2}{|c|}{ Non Agricultural } & \multirow{2}{*}{$\begin{array}{c}\text { Agricultural } \\
(5)\end{array}$} & \multirow{2}{*}{$\begin{array}{c}\text { Non-Agricultural } \\
(6)\end{array}$} \\
\hline & (1) & $(2)$ & (3) & $(4)$ & & \\
\hline \multirow[t]{2}{*}{ Grain Suit x Born 1960} & -0.254 & -0.428 & -0.0351 & -0.160 & -0.393 & -0.141 \\
\hline & $(0.0719)$ & $(0.0913)$ & $(0.0578)$ & $(0.0980)$ & $(0.0951)$ & $(0.102)$ \\
\hline \multirow[t]{2}{*}{ Ln Dist to Big City x Born 1960} & & & & & 0.0492 & 0.0230 \\
\hline & & & & & $(0.0188)$ & $(0.0251)$ \\
\hline Province FE $x$ Year FE & $\mathrm{N}$ & $\mathrm{Y}$ & $\mathrm{N}$ & $\mathrm{Y}$ & $\mathrm{N}$ & $\mathrm{N}$ \\
\hline Observations & 46212 & 36748 & 35175 & 21198 & 36748 & 21198 \\
\hline R-squared & 0.907 & 0.895 & 0.892 & 0.865 & 0.895 & 0.865 \\
\hline
\end{tabular}

All regressions control for birth year and county fixed

effects.

Standard errors are clustered at the county level. 
Table 6: Example of Grain Production and Famine Mortality

\begin{tabular}{lcc}
\hline \hline & Village A & Village B \\
\hline Subsistence Needs & 100 & 100 \\
Average Annual Production 1954-48 & 130 & 100 \\
1959 Procurement Target = 10\% Increase from past production & 143 & 110 \\
1959 Actual Production = 13\% fall from previous years & 113.1 & 87 \\
Procurement = Target - Subsistence & 43 & 10 \\
Retention = Actual Production - Procurement & 70.1 & 77 \\
$\%$ Below Subistence = (Retention-Subsistence)/Subsistence & $-29.90 \%$ & $-23.00 \%$ \\
\hline
\end{tabular}


Figure 1: Population and Aggregate Production 1949-76

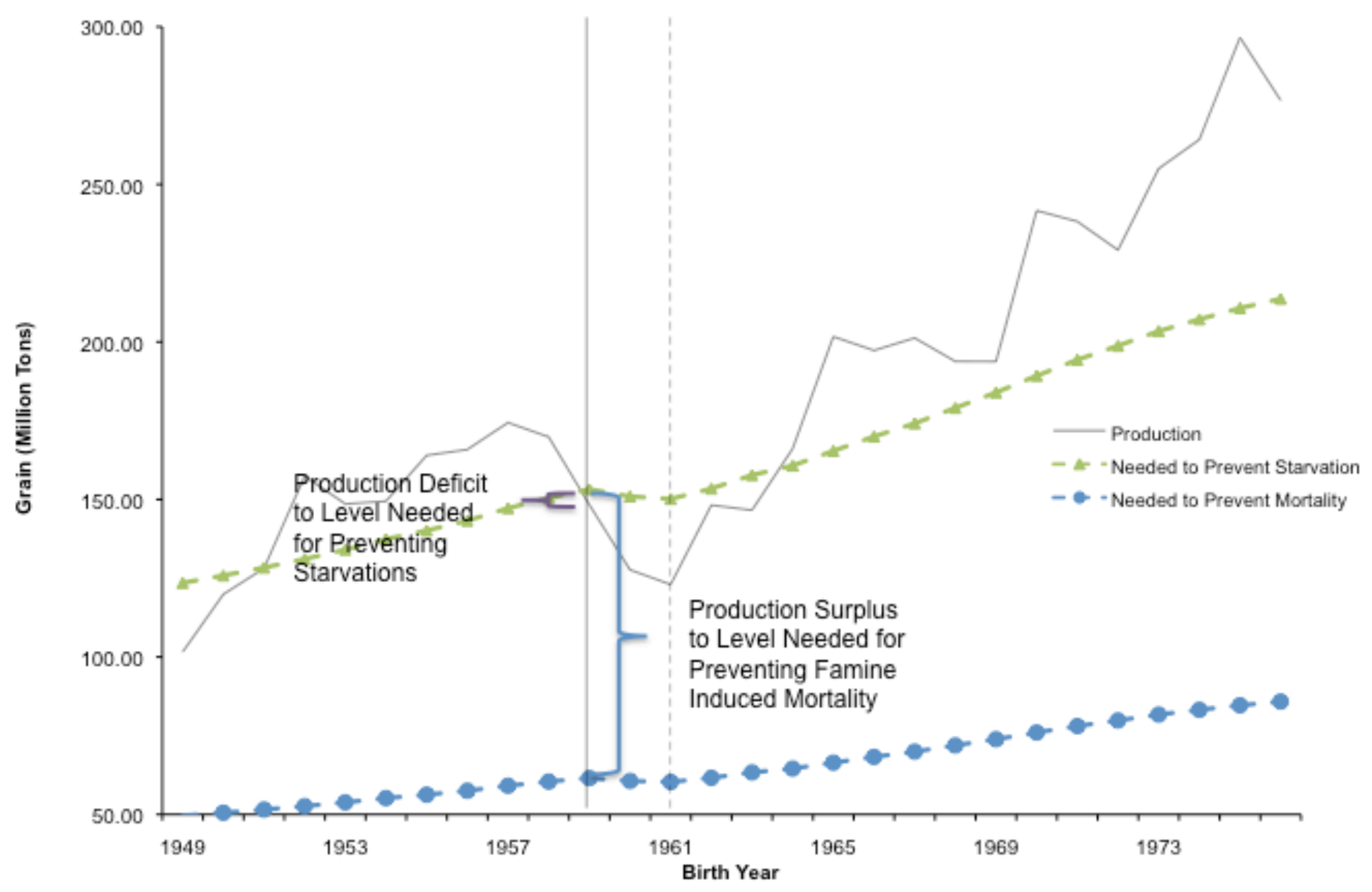

Source: The CPIRC and Comprehensive Statistical Data and Materials on 50 years of New China (1999) 
Figure 2A: Correlation between Province Level Mortality and Grain Production in 1959

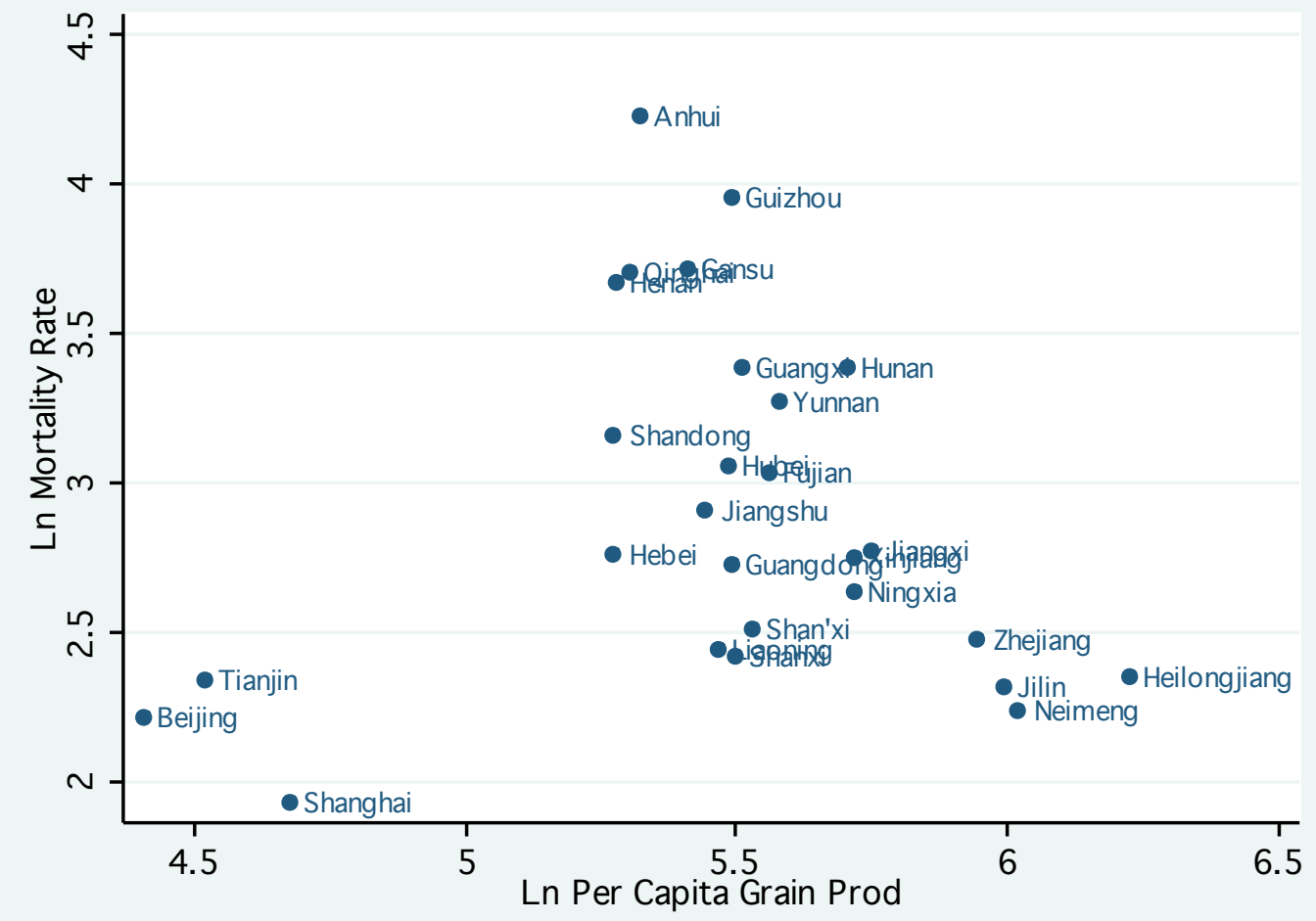

Source: Comprehensive Statistical Data and Materials on 50 years of New China (1999)

Figure 2B: Residual Plot of Bivariate Regression between Mortality and Grain Production in 1959

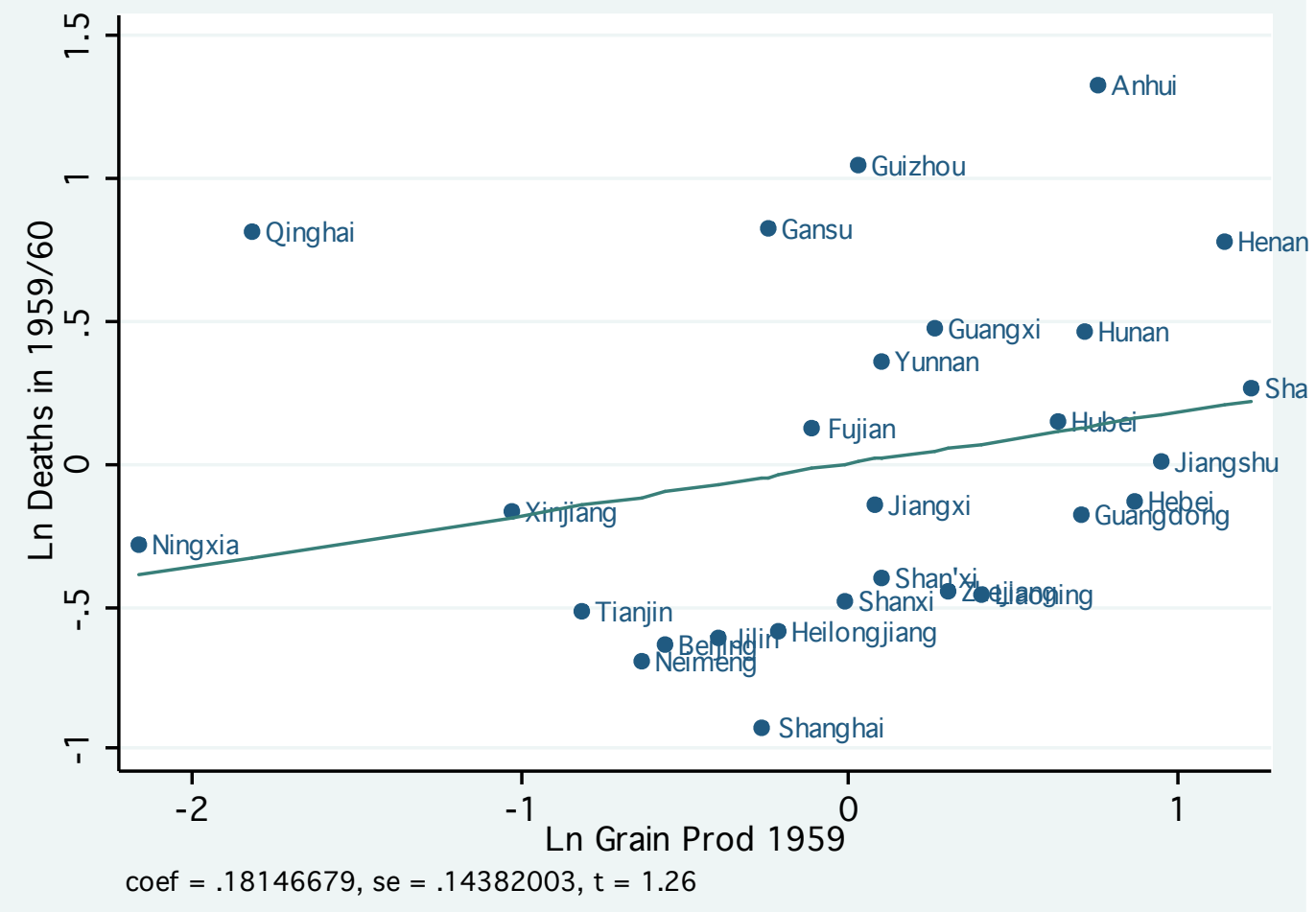

Source: Authors' calculations based on Comprehensive Statistical Data and Materials on 50 years of New China (1999) 
Figure 3A: Correlation between the Percentage Fall in Grain Production in 1959 and Average Annual Production during 1954-58

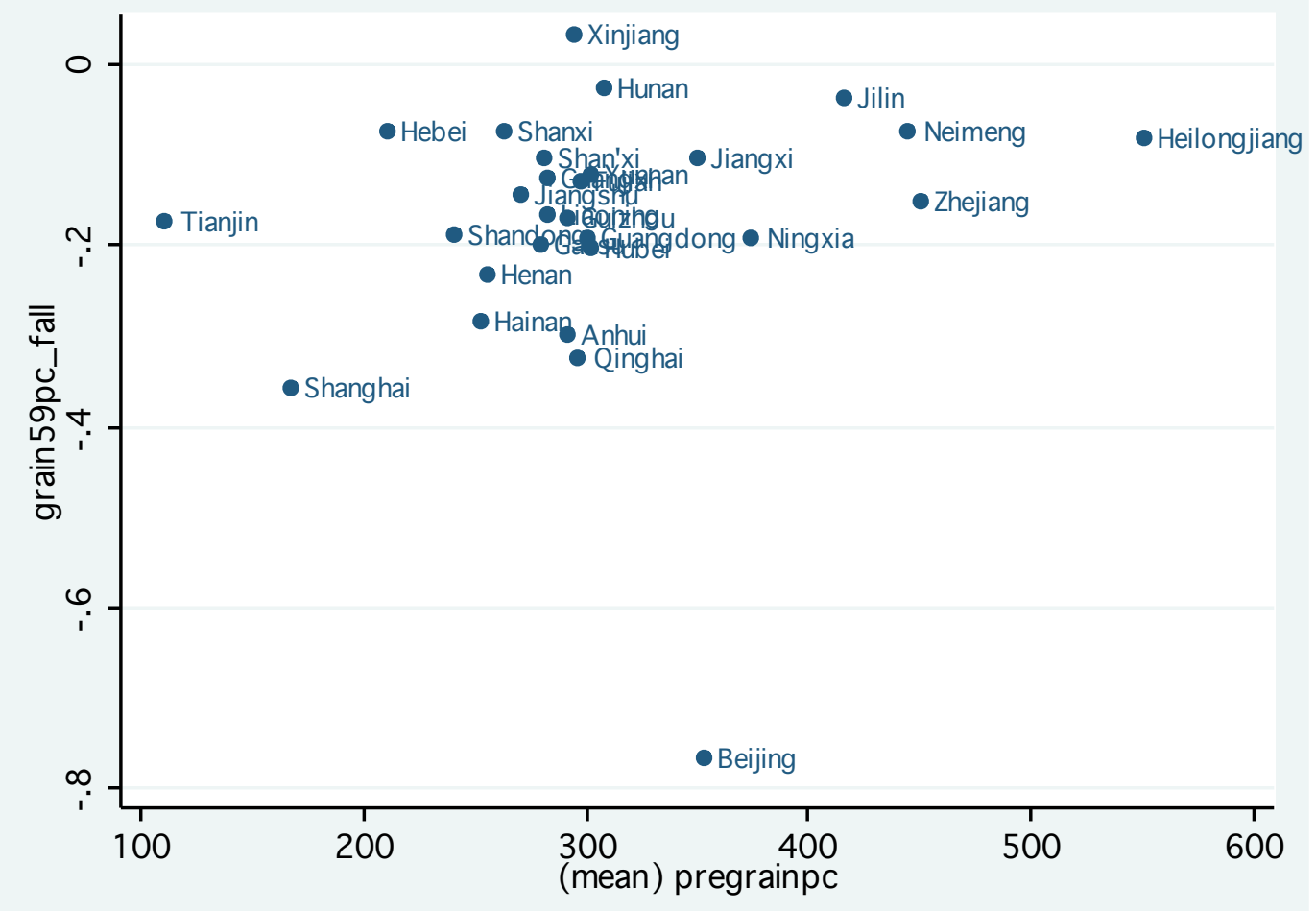

Source: Comprehensive Statistical Data and Materials on 50 years of New China (1999)

Figure 3B: Residual Plot from Bivariate Regression of the Percentage Fall in Grain Production in 1959 and Average Annual Production during 1954-58

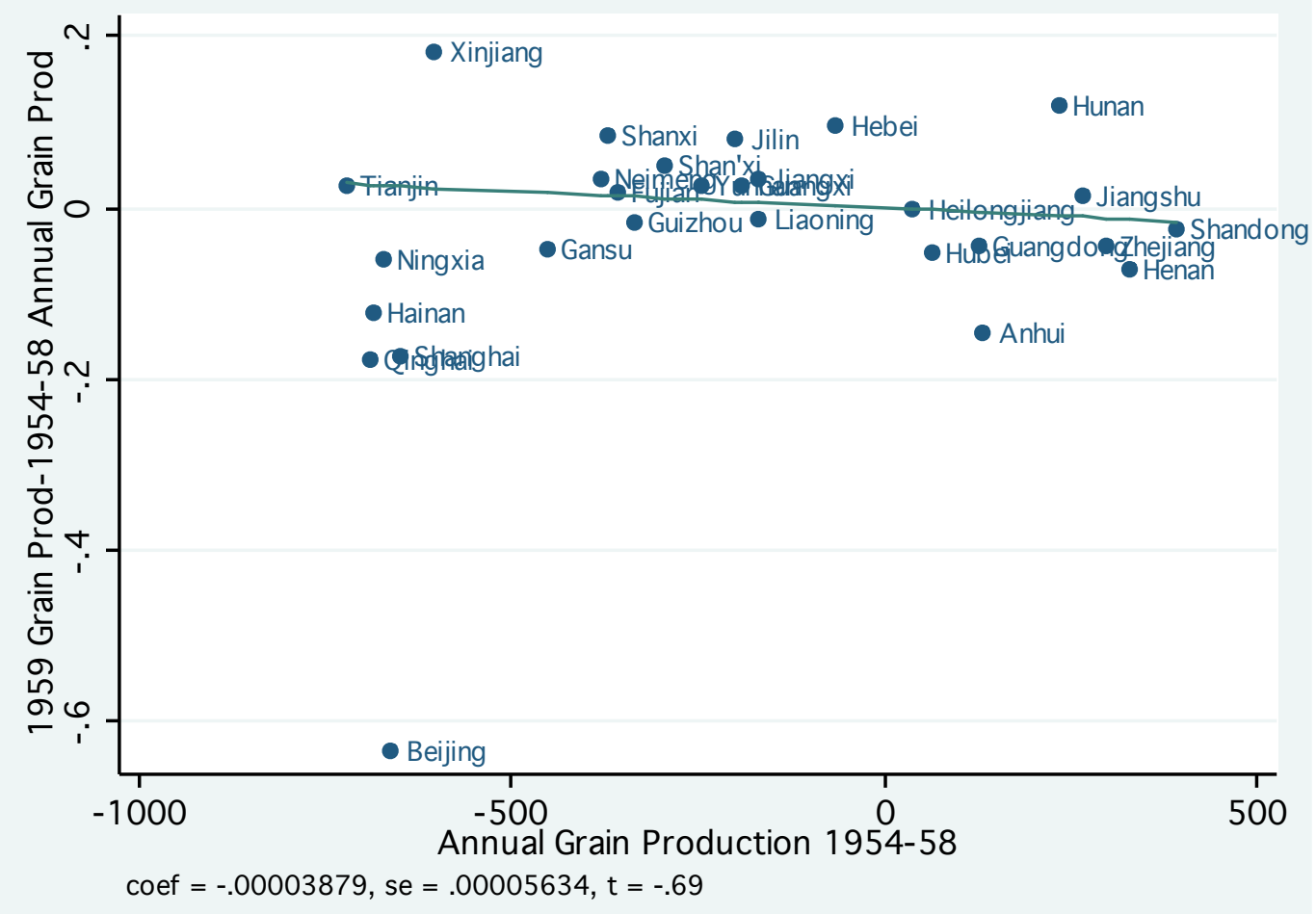

Source: Authors' calculation. 
Figure 4: Historical Grain Production in 21 Provinces (Li and Yang, 2005)

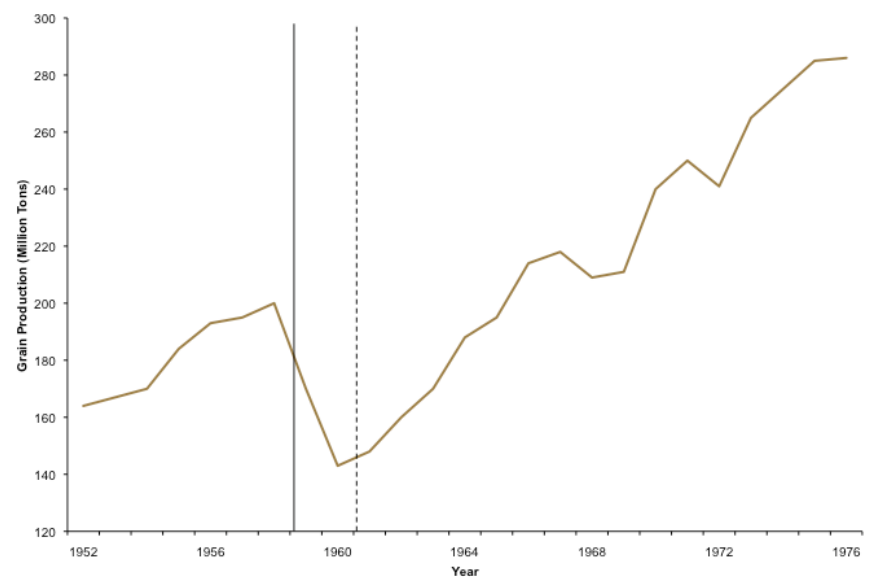

Figure 4B: Historical Grain Procurement (Li and Yang, 2005)

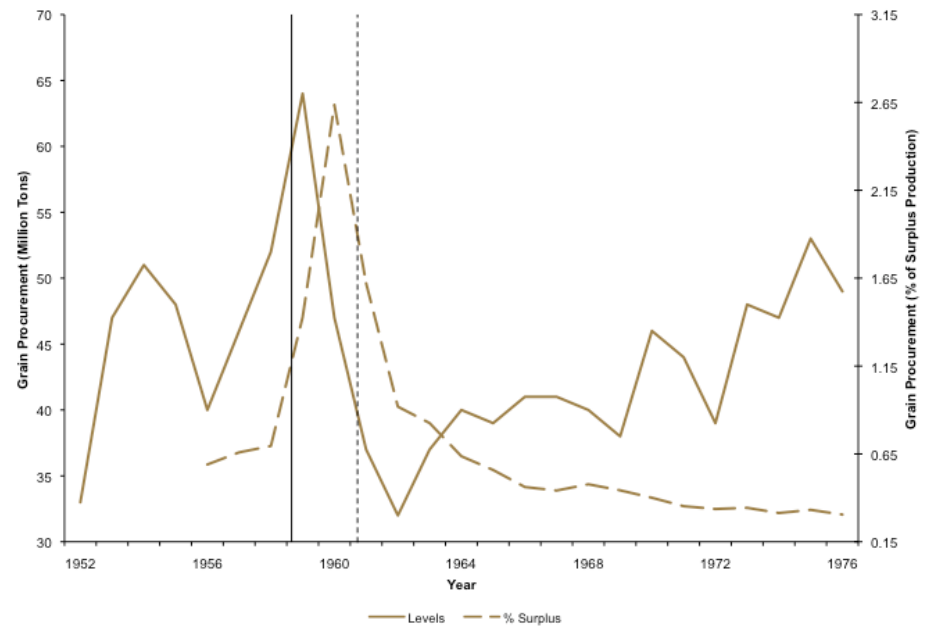

Figure 4C: Historical Retention (Li and Yang, 2005)

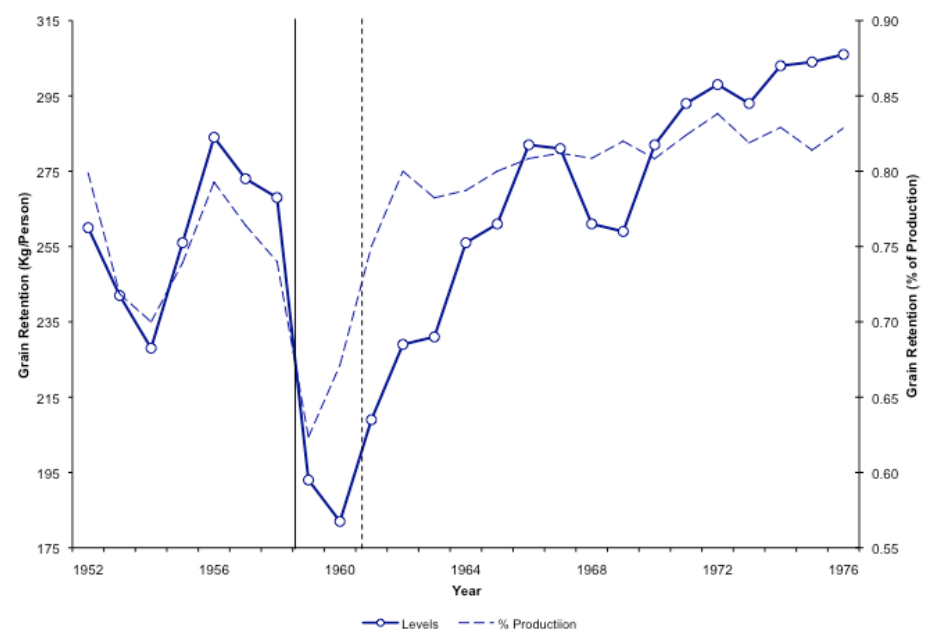


Figure 5A: Historical Province Level Mortality
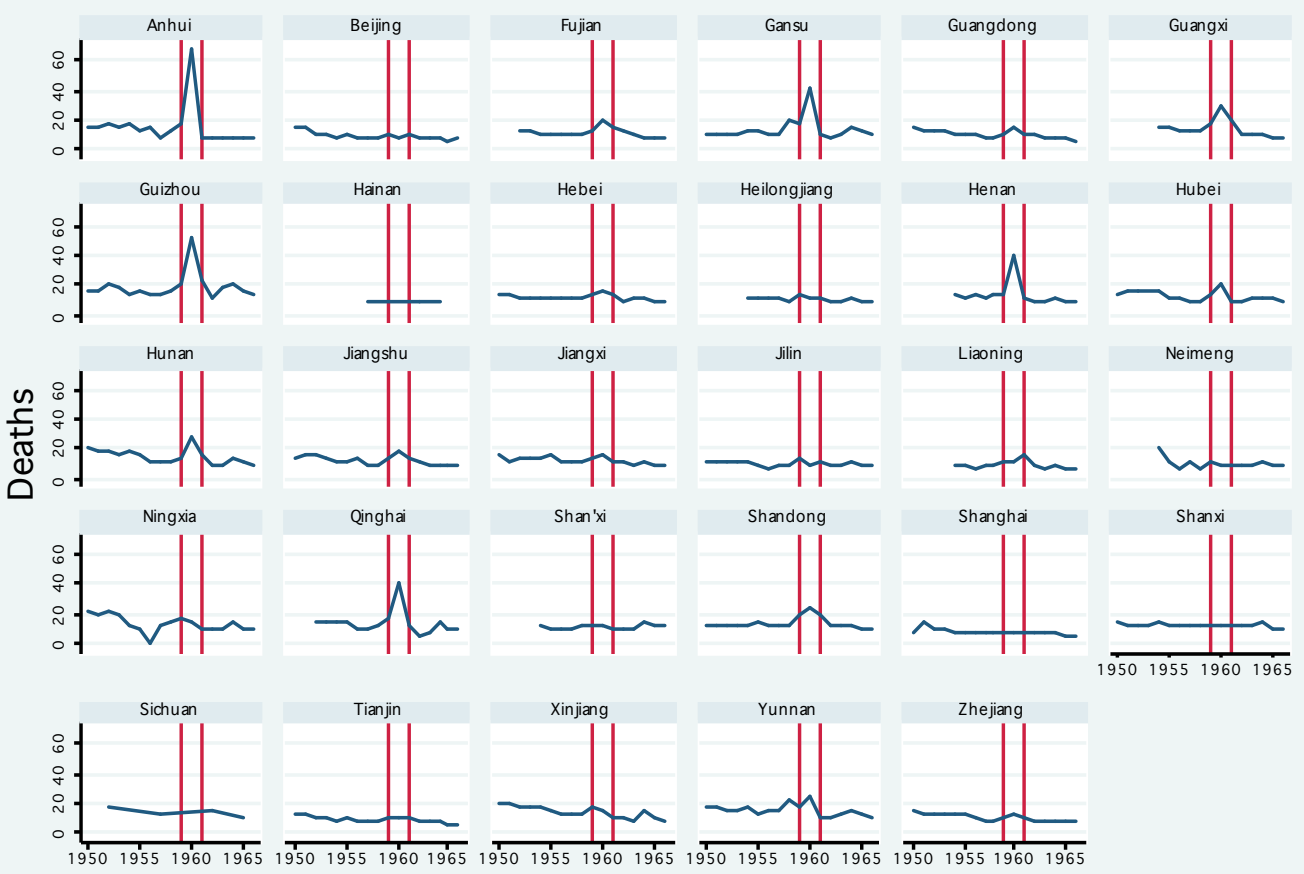

Graphs by Province

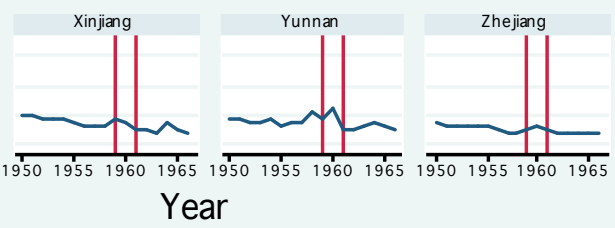

Source: Comprehensive Statistical Data and Materials on 50 years of New China (1999)

Figure 5B: Historical Province Level Grain Production
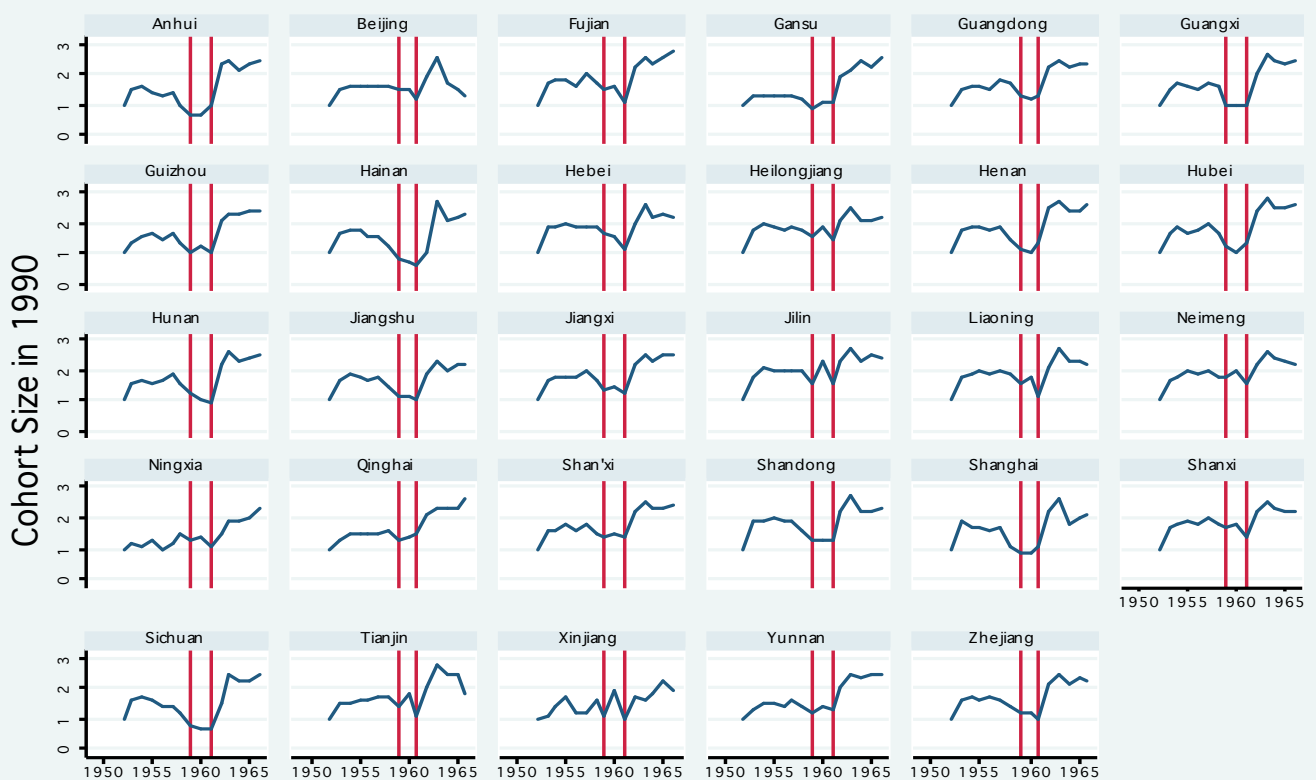

Graphs by Province
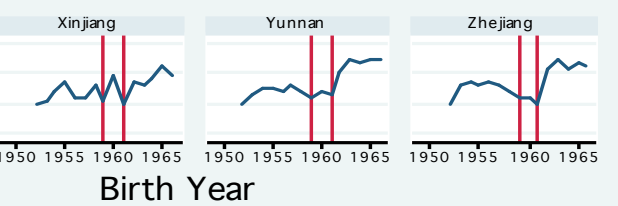

Birth Year

Source: Authors calculations based on the 1990 Population Census 
Figure 6A: Birth Cohort Size in the 1990 Population Census

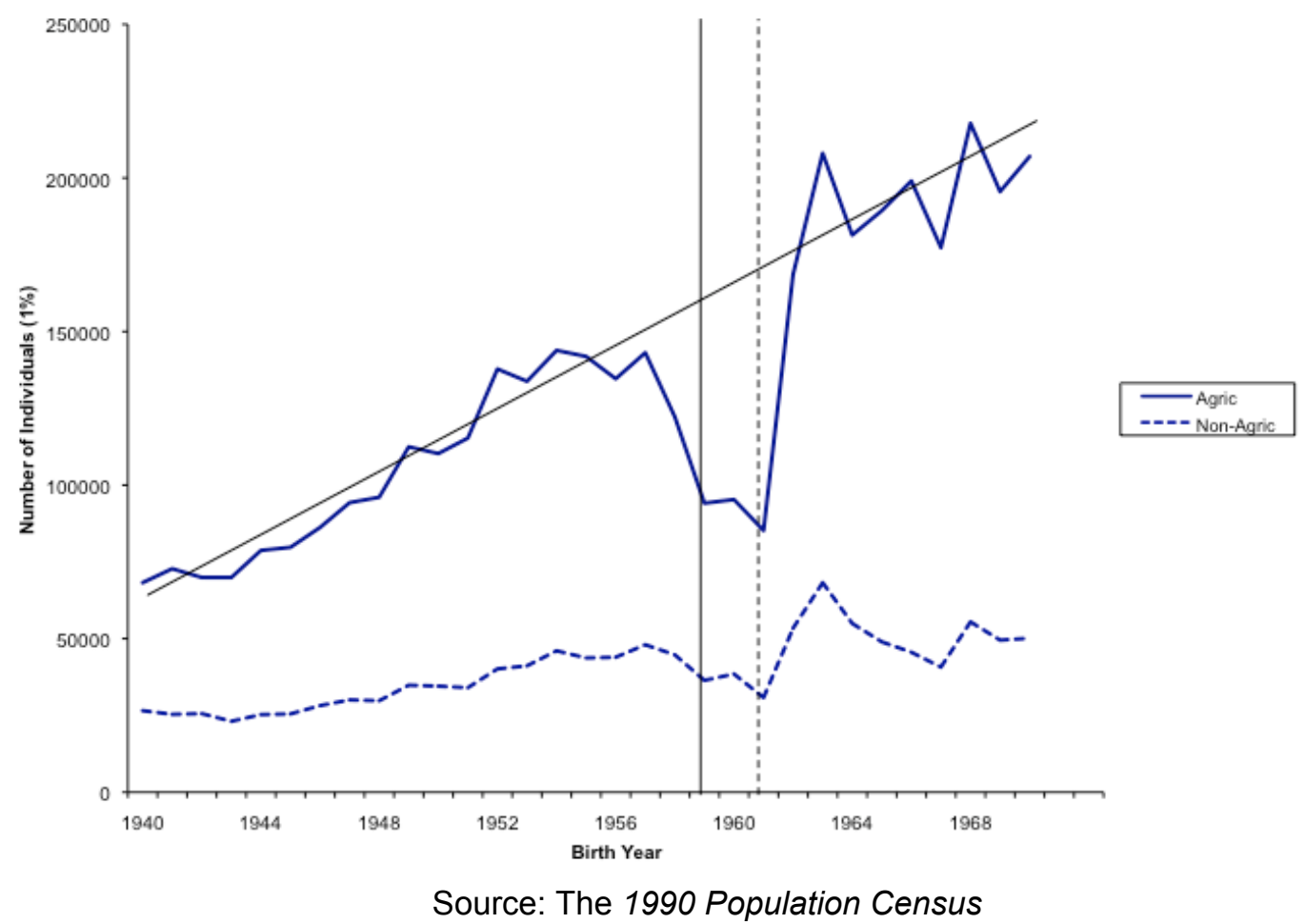

Figure 6B: Histogram of Famine Cohort Size Relative to Pre-Famine Cohort Size for Agricultural Households at the County Level

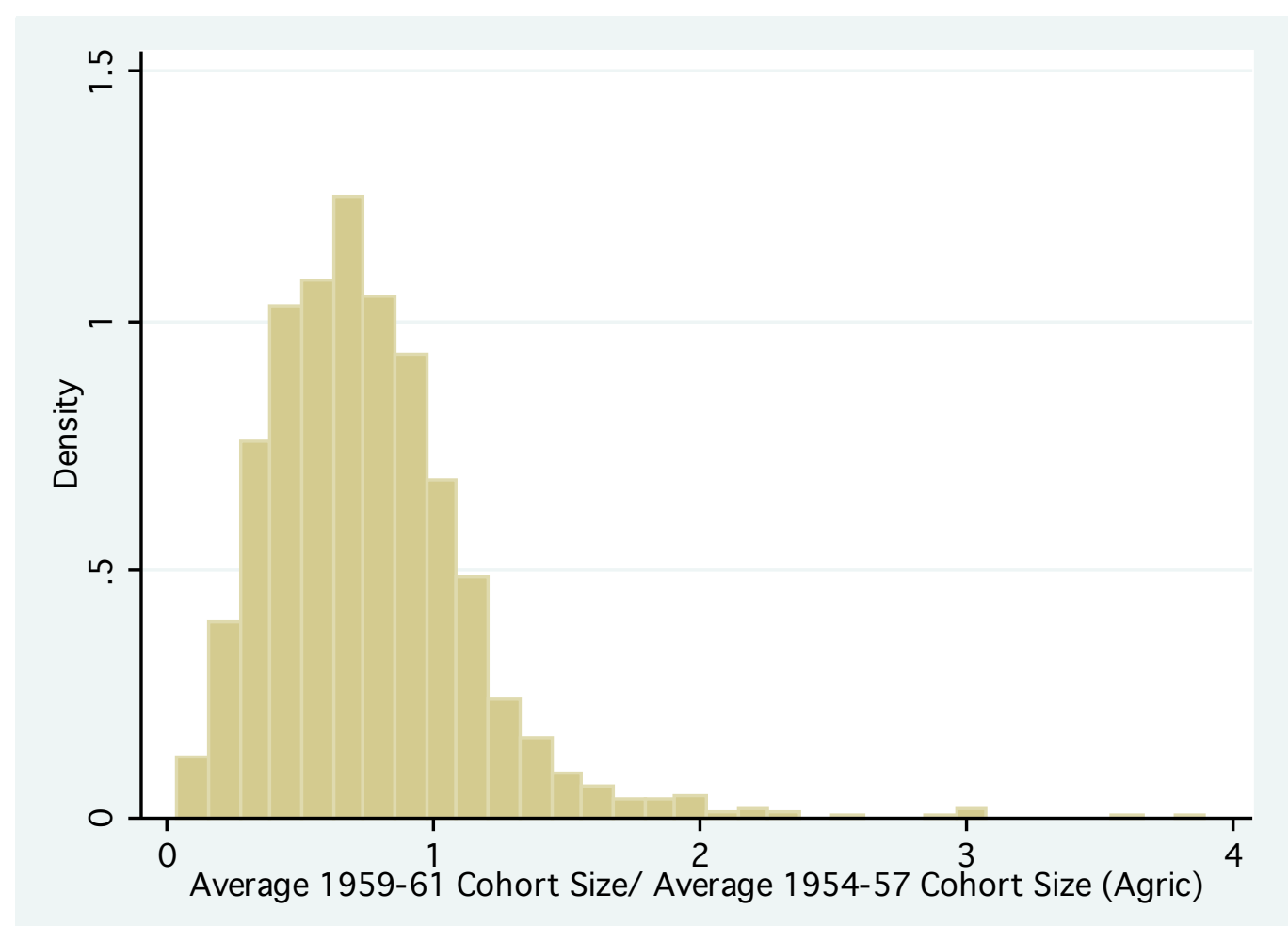

Source: The 1990 Population Census 
Figure 7A: The Correlation between Grain Suitability and Cohort Size at the County Level for Agricultural Households

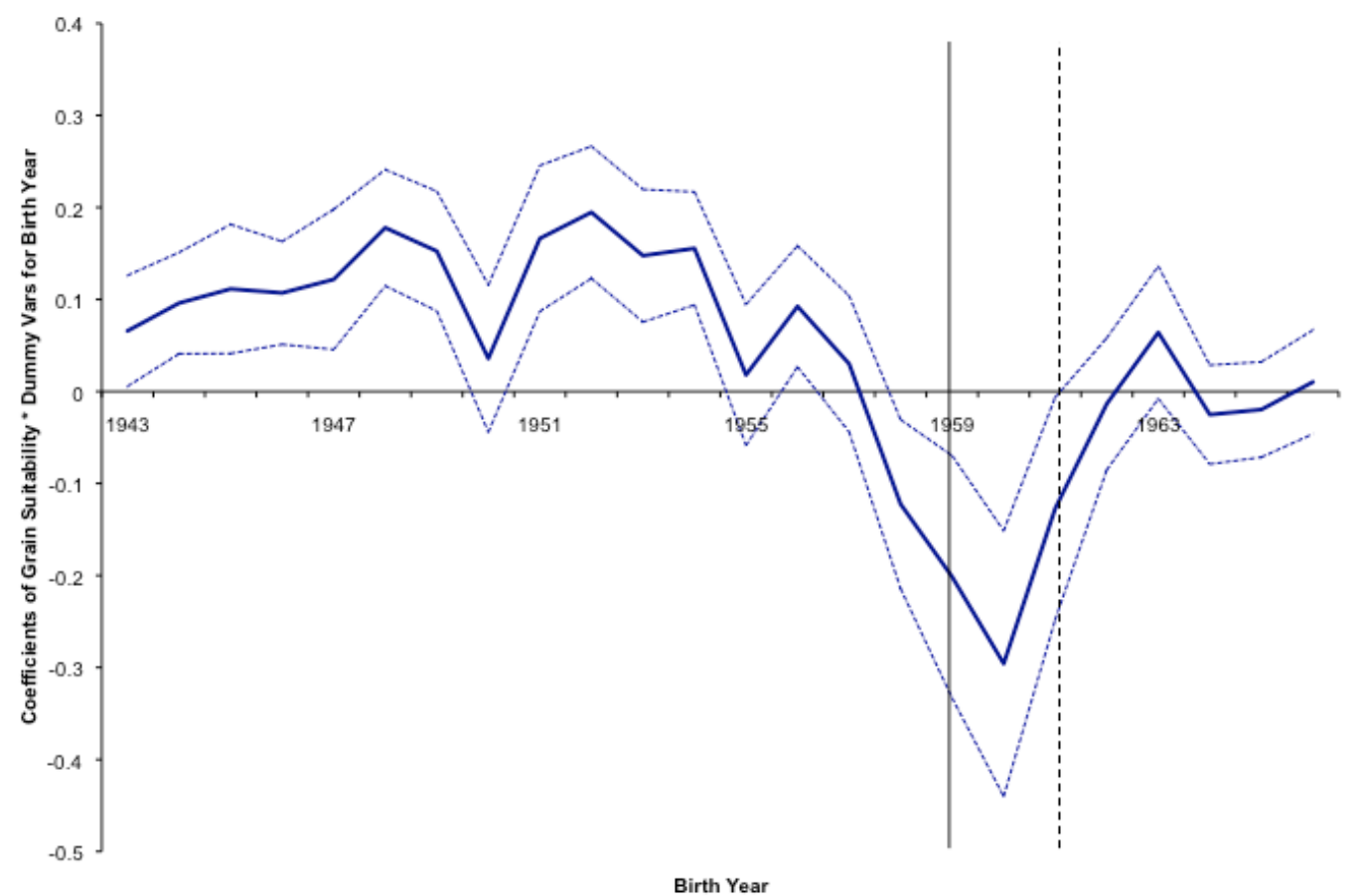

Source: Authors calculations

Figure 7B: The Correlation between Grain Suitability and Cohort Size at the County Level for Agricultural and Non-Agricultural Households

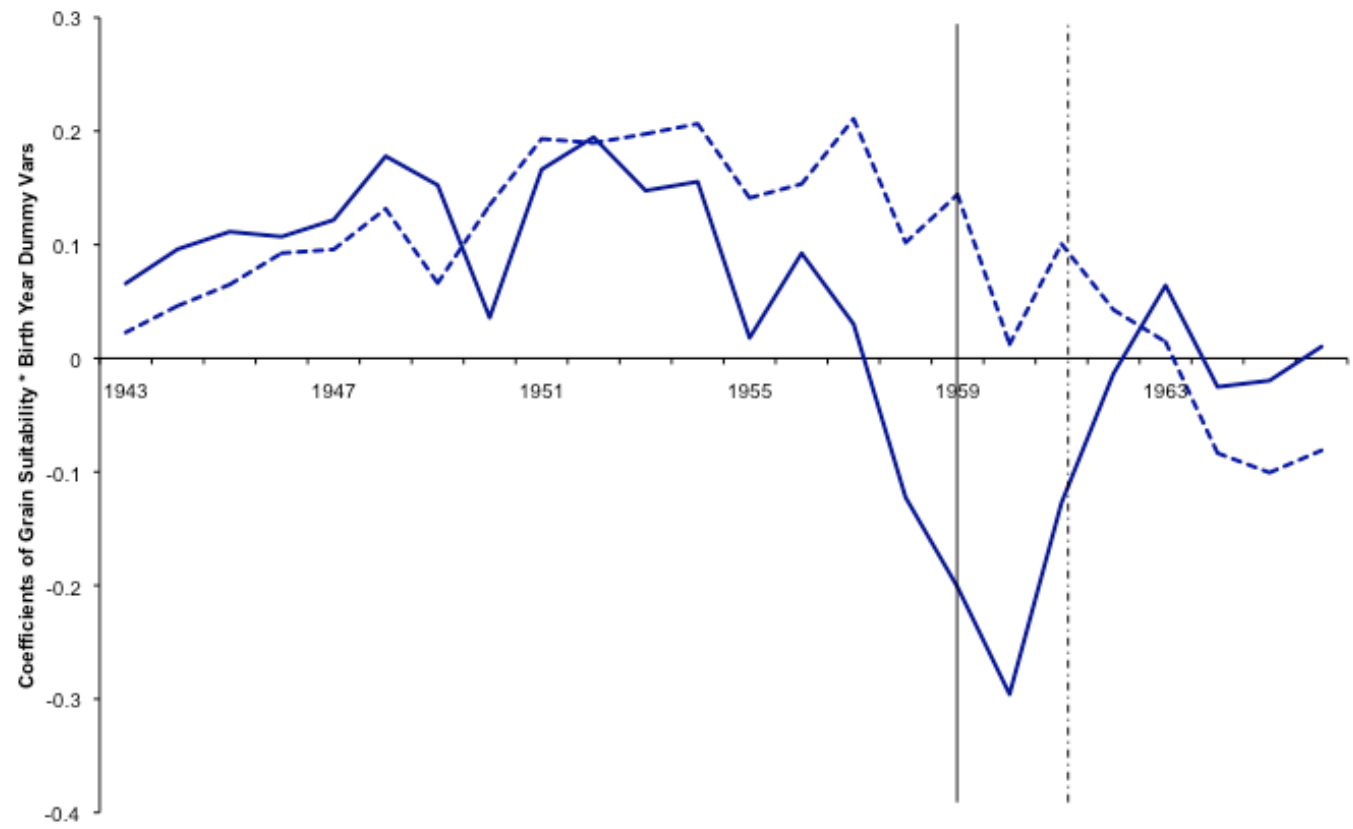

Birth Year

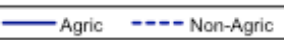

Source: Authors calculations 
Figure 8: The Correlation between Procurement Targets and Past Production at the Province Level

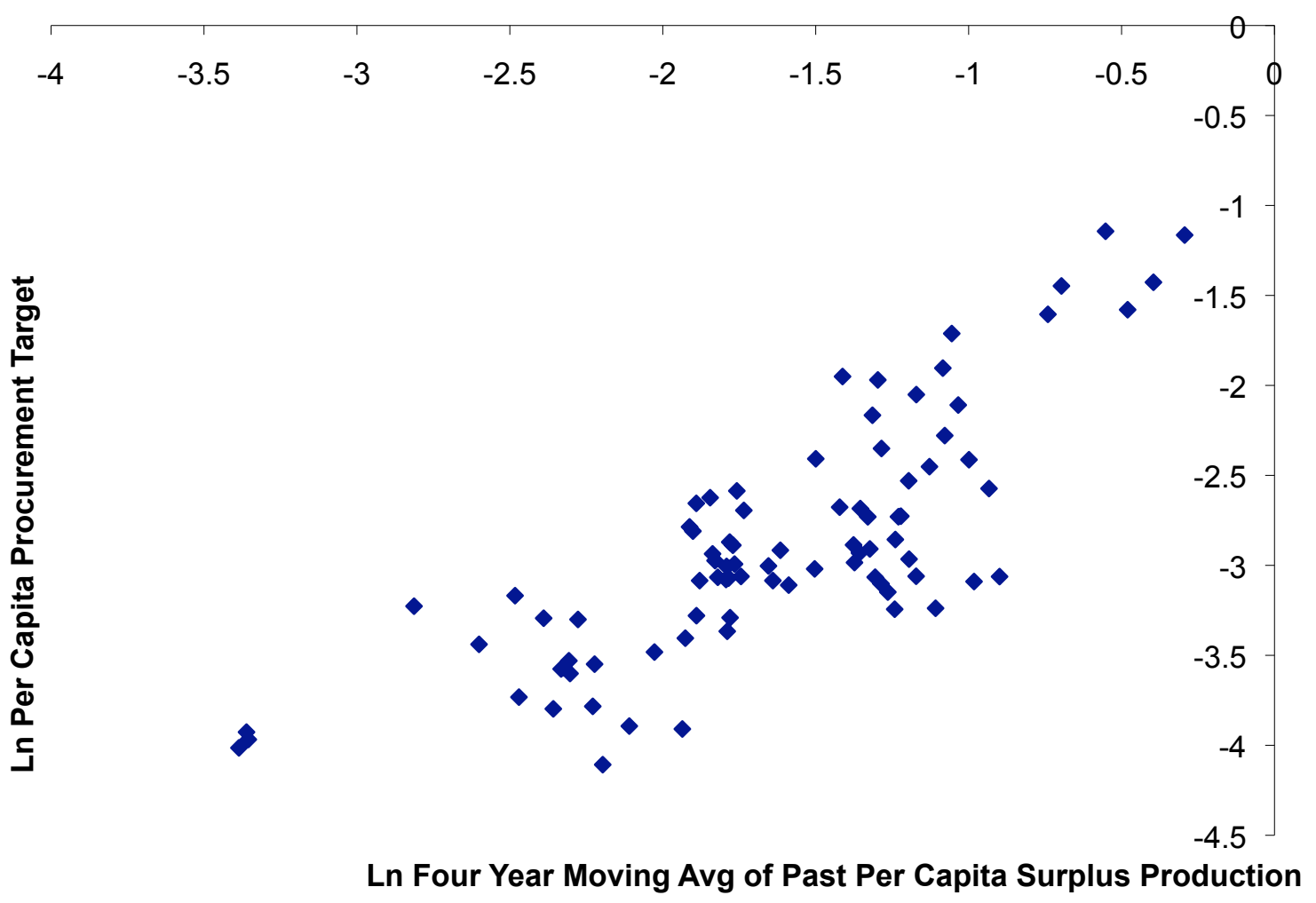

Source: Authors calculations 
Appendix Table A1: The Correlation between Suitability for Grain Cultivation Cohort Size

\begin{tabular}{|c|c|c|}
\hline & \multicolumn{2}{|c|}{ Dependent Variable: Ln Cohort Size } \\
\hline & (1) & (2) \\
\hline & Agric $\mathrm{HH}$ & Non-Agric $\mathrm{HH}$ \\
\hline \multirow[t]{2}{*}{ Grain Suit x Born 1943} & 0.0283 & 0.118 \\
\hline & $(0.0410)$ & $(0.0501)$ \\
\hline \multirow[t]{2}{*}{ Grain Suit x Born 1944} & 0.114 & 0.0756 \\
\hline & $(0.0394)$ & $(0.0519)$ \\
\hline \multirow[t]{2}{*}{ Grain Suit x Born 1945} & 0.0916 & 0.0512 \\
\hline & $(0.0460)$ & $(0.0587)$ \\
\hline \multirow[t]{2}{*}{ Grain Suit x Born 1946} & 0.130 & 0.167 \\
\hline & $(0.0399)$ & $(0.0557)$ \\
\hline \multirow[t]{2}{*}{ Grain Suit x Born 1947} & 0.129 & 0.136 \\
\hline & $(0.0395)$ & $(0.0601)$ \\
\hline \multirow[t]{2}{*}{ Grain Suit x Born 1948} & 0.252 & 0.149 \\
\hline & $(0.0381)$ & $(0.0561)$ \\
\hline \multirow[t]{2}{*}{ Grain Suit x Born 1949} & 0.206 & 0.157 \\
\hline & $(0.0396)$ & $(0.0563)$ \\
\hline \multirow[t]{2}{*}{ Grain Suit x Born 1950} & 0.110 & 0.225 \\
\hline & $(0.0442)$ & $(0.0649)$ \\
\hline \multirow[t]{2}{*}{ Grain Suit x Born 1951} & 0.343 & 0.264 \\
\hline & $(0.0413)$ & $(0.0631)$ \\
\hline \multirow[t]{2}{*}{ Grain Suit x Born 1952} & 0.292 & 0.304 \\
\hline & $(0.0449)$ & $(0.0707)$ \\
\hline \multirow[t]{2}{*}{ Grain Suit x Born 1953} & 0.291 & 0.334 \\
\hline & $(0.0454)$ & $(0.0654)$ \\
\hline \multirow[t]{2}{*}{ Grain Suit x Born 1954} & 0.251 & 0.308 \\
\hline & $(0.0428)$ & $(0.0681)$ \\
\hline \multirow[t]{2}{*}{ Grain Suit x Born 1955} & 0.143 & 0.288 \\
\hline & $(0.0441)$ & $(0.0630)$ \\
\hline \multirow[t]{2}{*}{ Grain Suit x Born 1956} & 0.251 & 0.307 \\
\hline & $(0.0434)$ & $(0.0663)$ \\
\hline \multirow[t]{2}{*}{ Grain Suit x Born 1957} & 0.180 & 0.379 \\
\hline & $(0.0463)$ & $(0.0677)$ \\
\hline \multirow[t]{2}{*}{ Grain Suit x Born 1958} & 0.0231 & 0.197 \\
\hline & $(0.0583)$ & $(0.0760)$ \\
\hline \multirow[t]{2}{*}{ Grain Suit x Born 1959} & -0.0639 & 0.188 \\
\hline & $(0.0685)$ & $(0.0716)$ \\
\hline \multirow[t]{2}{*}{ Grain Suit x Born 1960} & -0.169 & 0.0908 \\
\hline & $(0.0806)$ & $(0.0744)$ \\
\hline \multirow[t]{2}{*}{ Grain Suit x Born 1961} & -0.0200 & 0.131 \\
\hline & $(0.0587)$ & $(0.0700)$ \\
\hline \multirow[t]{2}{*}{ Grain Suit x Born 1962} & 0.0530 & 0.200 \\
\hline & $(0.0459)$ & $(0.0664)$ \\
\hline Grain Suit x Born 1963 & 0.140 & 0.319 \\
\hline & $(0.0426)$ & $(0.0728)$ \\
\hline Grain Suit x Born 1964 & -0.0192 & 0.0574 \\
\hline & $(0.0389)$ & $(0.0703)$ \\
\hline Grain Suit x Born 1965 & -0.0134 & 0.0428 \\
\hline & $(0.0390)$ & $(0.0707)$ \\
\hline Grain Suit x Born 1966 & -0.0260 & -0.0173 \\
\hline & $(0.0394)$ & $(0.0749)$ \\
\hline Observations & 46212 & 35175 \\
\hline R-squared & 0.907 & 0.893 \\
\hline
\end{tabular}

Regressions control for county and birth year fixed effects.

Standard errors are clustered at the county level. 
Figure A1A: Map of Suitability for Rice Cultivation

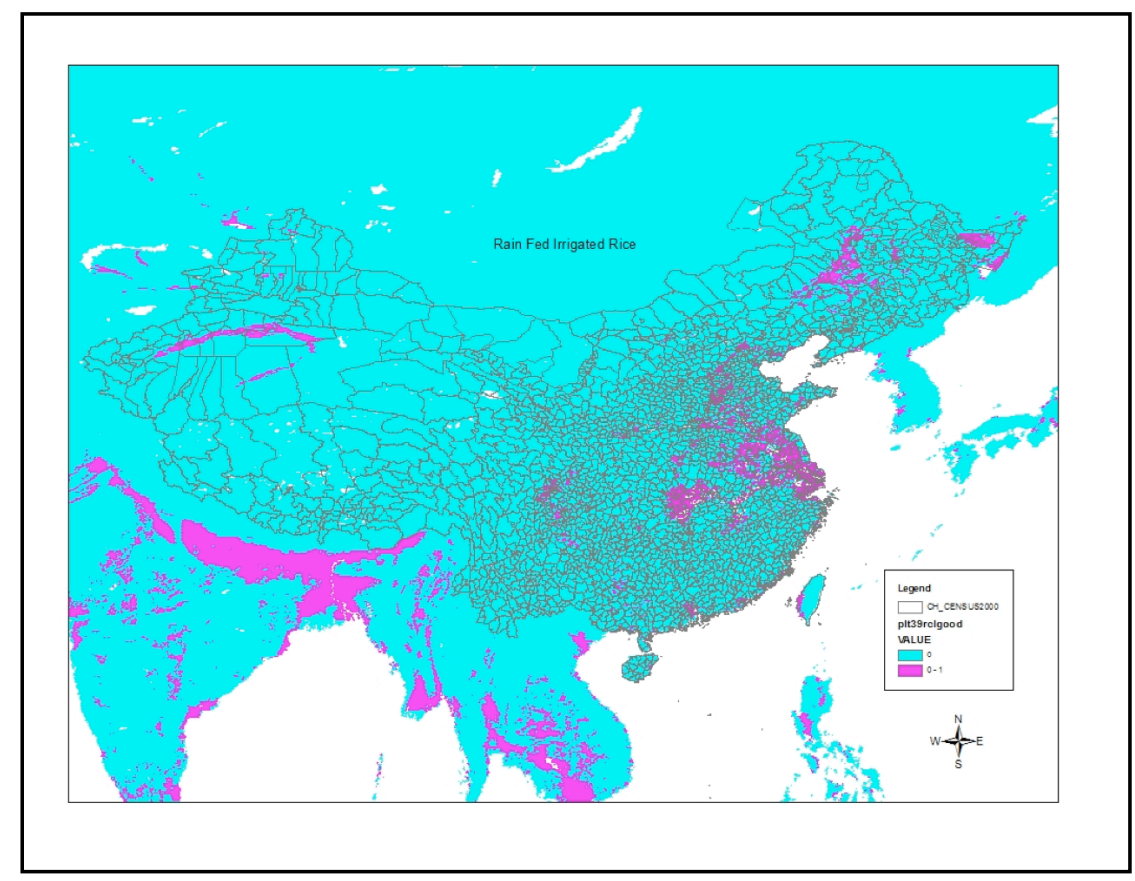

Source: Author's Calculations

Figure A1B: Map of Suitability for Wheat Cultivation

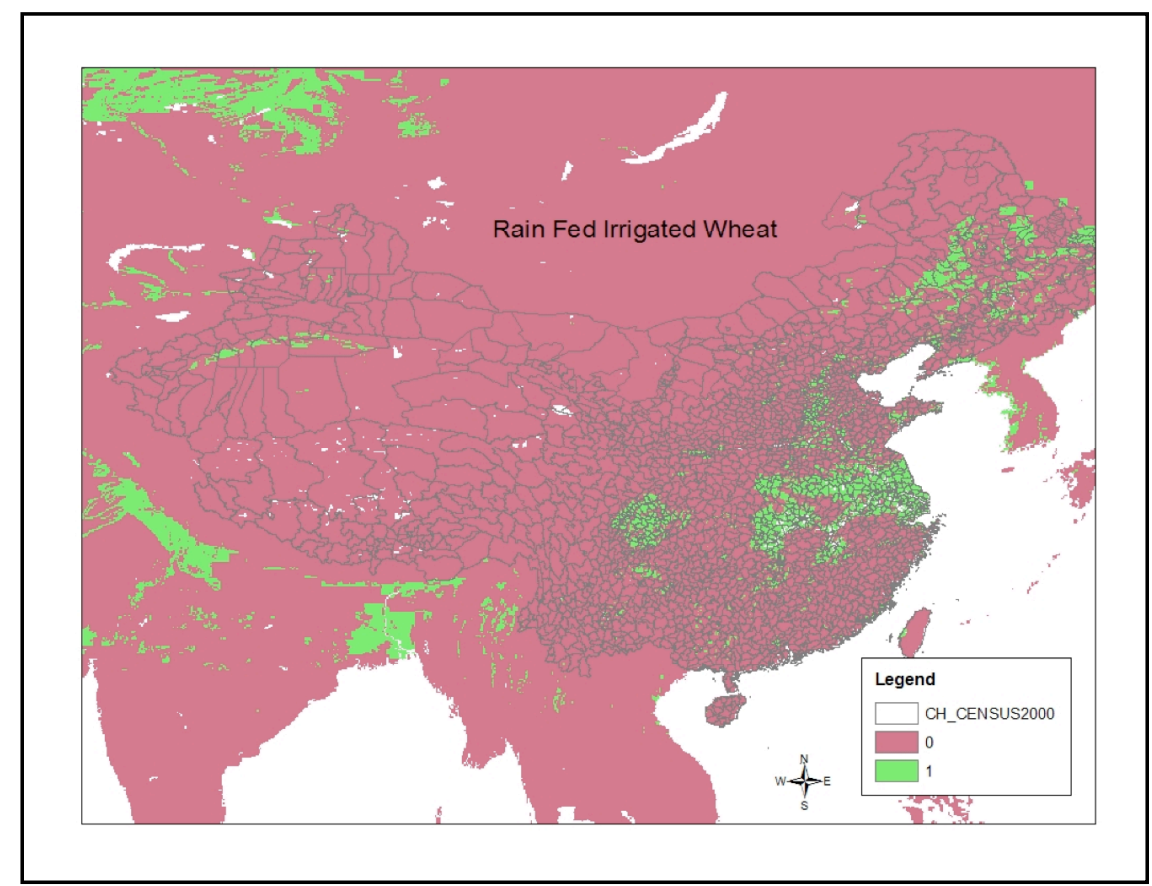

Source: Author's Calculations 